\title{
Ta-based 413 and 211 MAX phase solid solutions with $\mathrm{Hf}$ and $\mathrm{Nb}$
}

Matteo Griseri ${ }^{\star a, b}$, Bensu Tunca ${ }^{a, b}$, Shuigen Huang ${ }^{b}$, Martin Dahlqvist ${ }^{c}$, Johanna Rosén $^{c}$, Jun Lu ${ }^{c}$, Per O.Å. Persson ${ }^{c}$, Lucia Popescu ${ }^{a}$, Jozef Vleugels ${ }^{b}$ and Konstantina Lambrinou ${ }^{\mathrm{a}, \mathrm{d}}$

a SCK·CEN, Boeretang 200, $2400 \mathrm{Mol}$, Belgium

${ }^{b}$ KU Leuven, Dept. of Materials Engineering, Kasteelpark Arenberg 44, 3001 Leuven, Belgium

${ }^{c}$ Dept. of Physics, Chemistry and Biology, Linköping University, SE-581 83 Linköping, Sweden

${ }^{\mathrm{d}}$ School of Computing and Engineering, University of Huddersfield, Huddersfield HD1 3DH, UK

*Corresponding author: matteo.griseri@kuleuven.be

\begin{abstract}
New bulk MAX phase-based ceramics were synthesized in the $\mathrm{Ta}-\mathrm{Hf}-\mathrm{Al}-\mathrm{C}$ and $\mathrm{Ta}-$ $\mathrm{Nb}-\mathrm{Al}-\mathrm{C}$ systems. Specifically, $\left(\mathrm{Ta}_{1-\mathrm{x}}, \mathrm{Hf}_{\mathrm{x}}\right)_{4} \mathrm{AlC}_{3}$ and $\left(\mathrm{Ta}_{1-\mathrm{x}}, \mathrm{Nb}_{\mathrm{x}}\right)_{4} \mathrm{AlC}_{3}$ stoichiometries with $\mathrm{x}=0.05,0.1,0.15,0.2,0.25$ were targeted by reactive hot pressing of $\mathrm{Ta}_{2} \mathrm{H}, \mathrm{HfH}_{2}$, $\mathrm{NbH}_{0.89}, \mathrm{Al}$ and $\mathrm{C}$ powder mixtures at $1550^{\circ} \mathrm{C}$ in vacuum. The produced ceramics were characterized in terms of phase composition and microstructure by X-ray diffraction, scanning electron microscopy, electron probe microanalysis and scanning transmission electron microscopy. The investigation confirmed the existence of such M-site solid solutions with low solute concentrations, as predicted by first-principles calculations. These calculations also predicted a linear trend in lattice parameter evolution with increasing $\mathrm{Hf}$ concentration, in agreement with the experimental results. In order to increase the low phase purity of the produced ceramics, $\mathrm{Sn}$ was added to form $\left(\mathrm{Ta}_{1}\right.$. $\left.{ }_{x}, \mathrm{Hf}_{\mathrm{x}}\right)_{4}\left(\mathrm{Al}_{0.5}, \mathrm{Sn}_{0.5}\right) \mathrm{C}_{3}$ and $\left(\mathrm{Ta}_{1-\mathrm{x}}, \mathrm{Nb}_{\mathrm{x}}\right)_{4}\left(\mathrm{Al}_{0.5}, \mathrm{Sn}_{0.5}\right) \mathrm{C}_{3}$ double solid solutions, thus resulting in a higher content of the 413 MAX phase compounds in the produced ceramics.
\end{abstract}

Keywords: MAX Phases, Tantalum, Hafnium, Niobium, $\mathrm{Ta}_{4} \mathrm{AlC}_{3}$

\section{Introduction}

The ternary carbides/nitrides known as the $\operatorname{MAX}\left(M_{n+1} A X_{n}\right)$ phases have been attracting a lot of attention, due to their unique properties and wide range of potential applications. In the $M_{n+1} A X_{n}$ phases, $M$ is an early transition metal, $A$ is a semimetal or metalloid, $X$ is carbon or nitrogen, while the exact stoichiometry is defined by $n=1,2$ or $3[1,2]$. Solid solutions of two or more elements are possible on the $M, A$ and $X$ sites, generating an impressively large number of possible compositions, several of which have already been experimentally synthesized [1,2]. A two-element solid solution on the M-site could be described by the $\left(M_{1-x}, M_{x}^{\prime}\right)_{n+1}(A)(X)_{n}$ general stoichiometry, where $x$ is the mole fraction of the M' secondary solute element. The present work focuses on the $\mathrm{Ta}-\mathrm{Hf}-\mathrm{Al}-\mathrm{C}$ and $\mathrm{Ta}-\mathrm{Nb}-\mathrm{Al}-\mathrm{C}$ systems, where the secondary $\mathrm{M}$ ' solute elements are $\mathrm{Hf}$ and $\mathrm{Nb}$, respectively.

The interest in $\mathrm{Hf}$-containing solid solutions was motivated by the request for new metallurgical processes capable of synthesizing bulk, phase-pure ceramics with tunable stoichiometries in the $\mathrm{Ta}-\mathrm{Hf}-\mathrm{C}$ system; such compounds have been identified by ab-initio studies as candidate ultra-high temperature ceramics (UHTCs) with melting 
points exceeding $3800^{\circ} \mathrm{C}[3,4]$. From an application point of view, new highly refractory Ta-based carbides may be employed as advanced target materials in isotope separation on-line (ISOL) facilities. ISOL is a technique for the production of exotic radioactive ion beams (RIBs) by a process of on-line evaporation and extraction of radioisotopes from a target material, such as $\mathrm{TaC}_{\mathrm{x}}$, which has been irradiated by an accelerated particle beam [5,6]. ISOL target materials are typically porous, so as to facilitate radioisotope evaporation and their transport to the detecting devices. Therefore, high melting point target materials are desirable, as a high melting point typically implies the delayed material densification at high temperatures (i.e., $2000^{\circ} \mathrm{C}$ and above) and pore closure over time, assuring a more release-efficient operation over longer service periods [7].

In previous studies, $\left(\mathrm{Ta}_{1-\mathrm{x}}, \mathrm{Hf}_{\mathrm{x}}\right) \mathrm{C}$ pseudo-binary carbide solid solutions were produced by spark plasma sintering (SPS) of TaC-HfC powder mixtures at temperatures above $2000^{\circ} \mathrm{C}$, with $x$ ranging from 0 to 1 [8]. However, due to a miscibility gap below $888^{\circ} \mathrm{C}$ [9], the solute $\mathrm{Hf}$ atoms cannot be homogeneously dispersed in the cubic TaC host lattice. Taking this into account, it was decided to investigate the miscibility of $\mathrm{Hf}$ with a ternary carbide, such as $\mathrm{Ta}_{4} \mathrm{AlC}_{3}$. The first aim of this study is to explore whether it would be possible to produce bulk MAX phase-based ceramics with the $\left(\mathrm{Ta}_{1-\mathrm{x}}, \mathrm{Hf}_{\mathrm{x}}\right)_{4} \mathrm{AlC}_{3}$ overall stoichiometry. These ceramics would then serve as precursors for the synthesis of pseudo-binary $\left(\mathrm{Ta}_{1-\mathrm{x}}, \mathrm{Hf}_{\mathrm{x}}\right)_{4} \mathrm{C}_{3}$ solid solutions, based on the known tendency of $\mathrm{Ta}$ based MAX phase compounds to decompose at high temperatures in vacuum due to the evaporation of $\mathrm{Al}$, as reported in recent work [10]. This study was also motivated by the fact that ternary Ta- and Hf-based MAX phase compounds (i.e., $\mathrm{Ta}_{2} \mathrm{AIC}, \mathrm{Hf}_{2} \mathrm{AIC}$, $\mathrm{Hf}_{3} \mathrm{AlC}_{2}$, and $\mathrm{Ta}_{4} \mathrm{AIC} \mathrm{C}_{3}$ ) have been produced as highly pure bulk ceramics by reactive uniaxial hot pressing (HP) of $\mathrm{Ta}_{2} \mathrm{H}-\mathrm{Al}-\mathrm{C}$ and $\mathrm{HfH}_{2}-\mathrm{Al}-\mathrm{C}$ powder mixtures [10-13].

The Ta-Hf-Al-C quaternary system has only been discussed in literature in terms of defining the equilibrium phase diagrams below $1000^{\circ} \mathrm{C}$ and considering the formation of complex carbides in that temperature domain, reporting only $\mathrm{M}_{2} \mathrm{AIX}$ phases with no solid solutions on the M-site [14].

The second aim of the study is to compare, in terms of achieved purity and solubility limits, $\mathrm{Ta}-\mathrm{Hf}-\mathrm{Al}-\mathrm{C}$ MAX phase solid solutions with similar compositions in the $\mathrm{Ta}-\mathrm{Nb}-$ $\mathrm{Al}-\mathrm{C}$ system. Unlike $\mathrm{Hf}$ and $\mathrm{Ta}, \mathrm{Nb}$ and $\mathrm{Ta}$ have identical atomic radii, with $\mathrm{NbC}$ and $\mathrm{TaC}$ binary carbides exhibiting a solid solubility over the full compositional range and forming mixed $\left(\mathrm{Ta}_{1-x}, \mathrm{Nb}_{\mathrm{x}}\right) \mathrm{C}$ pseudo-binary carbides [9]. Similar to the Hf-containing MAX phases, Nb-containing MAX phase compounds have been reported in literature, such as the ternary compounds $\mathrm{Nb}_{2} \mathrm{AIC}$ and $\mathrm{Nb}_{4} \mathrm{AlC}_{3}$ [1], as well as M-site solid solutions, such as $\left(\mathrm{Nb}_{1-\mathrm{x}}, \mathrm{Zr}_{\mathrm{x}}\right)_{4} \mathrm{AlC}_{3}$ with $\mathrm{x}=0.05,0.1,0.15,0.2$ and 0.25 [15], $\left(\mathrm{Nb}_{0.5}, \mathrm{Sc}_{0.5}\right)_{2} \mathrm{AIC}[16]$ and $\left(\mathrm{Nb}_{1-\mathrm{x}}, \mathrm{Ti}_{\mathrm{x}}\right)_{4} \mathrm{AlC} \mathrm{C}_{3}$ with $\mathrm{x}=0.2$ [17] and 0.3 [18].

Moreover, the synthesis of $\left(\mathrm{Ta}_{1-\mathrm{x}}, \mathrm{Hf}_{\mathrm{x}}\right)_{4}\left(\mathrm{Al}_{0.5}, \mathrm{Sn}_{0.5}\right) \mathrm{C}_{3}$ and $\left(\mathrm{Ta}_{1-\mathrm{x}}, \mathrm{Nb}_{\mathrm{x}}\right)_{4}\left(\mathrm{Al}_{0.5}, \mathrm{Sn}_{0.5}\right) \mathrm{C}_{3}$ double solid solutions was explored in an attempt to produce MAX phase-based bulk ceramics with higher phase purity. This approach has already been successfully implemented in the synthesis of double solid solution $(\mathrm{Zr}, \mathrm{Nb})_{2}(\mathrm{Al}, \mathrm{Sn}) \mathrm{C}$ and $(\mathrm{Zr}, \mathrm{Ti})_{2}(\mathrm{Al}, \mathrm{Sn}) \mathrm{C}$ MAX phase ceramics $[19,20]$.

In order to assess the formation of $413 \mathrm{MAX}$ phase compounds in the $\mathrm{Ta}-\mathrm{Hf}-\mathrm{Al}-\mathrm{C}$ and $\mathrm{Ta}-\mathrm{Nb}-\mathrm{Al}-\mathrm{C}$ systems, $\mathrm{Ta}_{2} \mathrm{H}, \mathrm{HfH}_{2}, \mathrm{NbH}, \mathrm{Al}$ and $\mathrm{C}$ (graphite) powders were mixed with varying relative amounts of $\mathrm{Hf}$ and $\mathrm{Nb}$. The powder mixtures were compacted and reaction hot pressed. The obtained materials were characterized by X-ray diffraction (XRD), and scanning electron microscopy (SEM) combined with energy \& wavelength 
dispersive X-ray spectroscopy (EDS \& WDS). Ultimately, select specimens were analyzed by scanning transmission electron microscopy (STEM) combined with EDS to obtain elemental maps from the areas of interest.

\section{Experimental procedure}

Tantalum hydride $\left(\mathrm{Ta}_{2} \mathrm{H}\right)$ powder was obtained by the hydrogenation of metallic $\mathrm{Ta}$ (particle size $<44 \mu \mathrm{m}$, purity $99.95 \%$, H.C. Starck) in pure $\mathrm{H}_{2}$ at $800^{\circ} \mathrm{C}$ for $2 \mathrm{~h}$. The brittle $\mathrm{Ta}_{2} \mathrm{H}$ powder was milled in a planetary ball mill (Retsch PM4-MA, Germany) for $30 \mathrm{~min}$ at $250 \mathrm{rpm}$, in isopropanol and in an air atmosphere, using zirconia milling balls ( $\varnothing 5 \mathrm{~mm}$ and $10 \mathrm{~mm}$ ) in a 3Y-TZP $\mathrm{ZrO}_{2}$ container. The maximum particle size was reduced from $50 \mu \mathrm{m}$ to $10 \mu \mathrm{m}$, in order to improve the mixing with the other constituents. The milled $\mathrm{Ta}_{2} \mathrm{H}$ was dried in a rotating evaporator (Heidolph 4010) and was sieved using a 32- $\mu \mathrm{m}$ fabric sieve.

The refined $\mathrm{Ta}_{2} \mathrm{H}$ powder was mixed with $\mathrm{HfH}_{2}$ (particle size $<10 \mu \mathrm{m}$, purity $>98 \%$, Rockwood Lithium, grade PS, Germany), $\mathrm{NbH}_{0.89}$ (particle size $<40 \mu \mathrm{m}, \mathrm{CBMM}$, Brazil), Al (particle size $<5 \mu \mathrm{m}$, purity $>99 \%$, Atlantic Equipment Engineers, USA), and graphite (particle size $<5 \mu \mathrm{m}$, purity $>99 \%$, Asbury Graphite Mills, USA) to obtain the various $\left(\mathrm{Ta}_{\mathrm{x}}, \mathrm{Hf}_{1-\mathrm{x}}\right)_{4} \mathrm{AlC}_{3}$ and $\left(\mathrm{Ta}_{\mathrm{x}}, \mathrm{Nb}_{1-\mathrm{x}}\right)_{4} \mathrm{AlC}_{3}$ starting powder compositions. A $25 \%$ molar excess of $\mathrm{Al}$ and a $13 \%$ substoichiometric $\mathrm{C}$ content were chosen to inhibit the formation of $\mathrm{TaC}_{y}, \mathrm{HfC}_{\mathrm{y}}$ and $\left(\mathrm{Ta}_{\mathrm{x}}, \mathrm{Hf}_{1-\mathrm{x}}\right) \mathrm{C}_{\mathrm{y}}$ carbides, as suggested previously $[10,15]$. For the synthesis of Sn-containing double solid solutions, metallic Sn powder (particle size $<5 \mu \mathrm{m}$, purity $>99 \%$, Atlantic Equipment Engineers, USA) was used.

As this work targeted the synthesis of Ta-rich $\left.\left(\mathrm{Ta}_{1-\mathrm{x}}, \mathrm{M}_{\mathrm{x}}\right)_{4}\right)_{4} \mathrm{AlC}_{3} \mathrm{MAX}$ phase solid solutions, the $\mathrm{Hf}$ and $\mathrm{Nb}$ secondary solute concentrations $\mathrm{x}$ were set at $0.05,0.1,0.15$, 0.2 and 0.25 . The different $\left(\mathrm{Ta}_{1-\mathrm{x}}, \mathrm{Hf}_{\mathrm{x}}\right)_{4} \mathrm{AlC}_{3}$ starting powder grades are herein referred to as "TH05" ( $x=0.05)$, "TH10" $(x=0.1)$, "TH15" $(x=0.15)$, "TH20" $(x=0.2)$, and "TH25" $(x=0.25)$. Similarly, the $\left(\mathrm{Ta}_{1-\mathrm{x}}, \mathrm{Nb}_{\mathrm{x}}\right)_{4} \mathrm{AlC}_{3}$ mixtures are referred to as "TN05" $(\mathrm{x}=$ 0.05), "TN10" ( $x=0.1)$, "TN15" $(x=0.15)$, "TN20" $(x=0.2)$, and "TN25" $(x=0.25)$.

The powder mixtures were cold-pressed into green pellets $(\varnothing 30 \mathrm{~mm}, 5-6 \mathrm{~mm}$ in thickness), under a load of $30 \mathrm{MPa}$, in a graphite die. Reaction sintering was performed in a hot press (W100/150-2200-50 LAX, FCT Systeme, Frankenblick, Germany) at $1550^{\circ} \mathrm{C}$ in vacuum $(0.4 \mathrm{mbar})$ for $30 \mathrm{~min}$ dwell time, after a heating ramp of $20^{\circ} \mathrm{C} / \mathrm{min}$. The uniaxial pressure of $30 \mathrm{MPa}$ was applied exclusively during the dwell time. Afterwards, the sintered compacts were allowed to cool naturally by switching off the power supply.

The produced materials were characterized by XRD in the $0^{\circ}$ to $75^{\circ} 2 \theta$ range, in steps of $0.01^{\circ}$, and at $0.2 \mathrm{~s} /$ step detection time, using a Cu $K_{\alpha}$ source operated at $40 \mathrm{kV}$ and $30 \mathrm{~mA}$ (Bruker D2 Phaser, Germany) on both polished bulk and milled powder samples. The carbide-rich surface reaction layer was removed by grinding the assintered discs prior to polishing and XRD analysis. Calculations of the predicted patterns and Rietveld refinement were performed using the MAUD software, obtaining $\mathrm{R}_{\mathrm{wp}}$ values ranging from $6 \%$ to $12 \%$ [21]. The XRD patterns used to calculate lattice parameters were measured from powders obtained by crushing the bulk specimens in a vibratory ring mill (Retsch RS 200, Germany).

The microstructure was examined on mirror-polished ceramics by SEM/EDS (XL30FEG, FEI). Since the $\mathrm{Hf}$ and Ta characteristic $\mathrm{X}$-ray signals cannot be differentiated by $E D S$, due to the similar energy of both $\mathrm{M}\left(65 \mathrm{eV}\right.$ difference) and $\mathrm{L}_{\alpha}$ (247 eV difference) transitions, the Hf-containing grades were also examined by WDS using an electron 
probe microanalyser (EPMA; JEOL Ltd, JXA-8530F, Japan) with a wavelength resolution of $0.155 \times 10^{-3} \mathrm{~nm}$ (as compared to the $5 \times 10^{-3} \mathrm{~nm}$ difference in $\mathrm{L}_{\alpha}$ characteristic X-rays). Select specimens were used for the extraction of thin foils using focused ion beam (FIB); the thin foils were investigated by transmission electron microscopy (STEM) and EDS, using the Linköping double-corrected FEI Titan ${ }^{3}$ 60-300, equipped with high-brightness gun (XFEG), monochromator, Super-X EDS detector and Quantum ERS-GIF.

All first-principles calculated energies were obtained based on the Vienna Ab initio Simulation Package (VASP 5.4.4) [22] implementation of density functional theory (DFT), using the Perdew-Burke-Ernzerhof (PBE) generalized gradient approximation (GGA) [23] description of the exchange-correlation energy. The plane wave energy cutoff was set to $400 \mathrm{eV}$, using $k$-point grids with a spacing of $0.05 \AA^{-1}$ according to the Monkhorst-Pack method [24]. The electronic energy convergence threshold was set to $10^{-6} \mathrm{eV} /$ atom for energy and $10^{-2} \mathrm{eV} / \AA ̊$ for force.

The Special Quasi-random Structures (SQS) method [25], as implemented in the Alloy Theoretic Automated Toolkit (ATAT) package [26], was used to generate representative supercell structures that approximated a fully random alloy of $\mathrm{Ta}$ and $\mathrm{M}^{\prime}$, with $\mathrm{M}^{\prime}=\mathrm{Nb}$ and $\mathrm{Hf}$ on the $\mathrm{M}$-sites of the $\left(\mathrm{Ta}_{1-\mathrm{x}}, \mathrm{M}_{\mathrm{x}}\right)_{2} \mathrm{AlC},\left(\mathrm{Ta}_{1-\mathrm{x}}, \mathrm{M}_{\mathrm{x}}\right)_{4} \mathrm{AlC}_{3}$, and $\left(\mathrm{Ta}_{1-}\right.$ $\left.{ }_{x}, \mathrm{M}_{\mathrm{x}}\right) \mathrm{C}$ stoichiometries. The SQS supercell, thus, represented the best possible periodic supercell that mimics the local pair and multisite correlation functions of a random alloy, under the constraint of a given supercell size $\mathrm{N}$.

The thermodynamic stability of $\left(\mathrm{Ta}_{1-\mathrm{x}}, \mathrm{M}_{\mathrm{x}}\right)_{2} \mathrm{AIC}$ and $\left(\mathrm{Ta}_{1-\mathrm{x}}, \mathrm{M}_{\mathrm{x}}\right)_{4} \mathrm{AlC}_{3} \mathrm{MAX}$ phase solid solutions was investigated at $0 \mathrm{~K}$ with respect to their decomposition into any combination of competing phases. To identify the set of most competing phases, known as the equilibrium simplex, a linear optimization procedure based on the simplex method was used under the constraint of a fixed MAX stoichiometry $[27,28]$. The stability of a MAX phase was quantified in terms of its formation enthalpy, $\Delta H$, by comparing its energy to the energy of the equilibrium simplex:

$$
\Delta \mathrm{H}=\mathrm{E} \text { (compound) }-\mathrm{E} \text { (equilibrium simplex), }
$$

where $\Delta H<0$ indicates a stable phase, while $\Delta H>0$ indicates either an unstable or, at best, metastable phase. The selection of competing phases includes all known elemental, binary, ternary, and quaternary phases within the herein considered quaternary systems. Hypothetical phases, based on compounds existing in similar systems and/or with neighboring elements in the periodic table, were also included as competing phases.

Other temperature-dependent effects on the formation enthalpy, such as lattice vibrations and electronic entropy, were deemed negligible, as their contributions to a phase, significant or not, tend to be cancelled out in the Gibbs free energy of formation term [29]. This approach has been proven to work exceptionally well for previous theoretical studies of both ternary and quaternary MAX phases [28,30-36]. However, since solid solutions were investigated and approximated through modelled disorder (SQS), the contribution of configurational entropy to the Gibbs free energy of formation, $\Delta \mathrm{G}$, at elevated temperature was approximated using:

$$
\Delta \mathrm{G}=\Delta \mathrm{H}-\mathrm{T} \Delta \mathrm{S},
$$

where $\mathrm{T}$ is the temperature and $\Delta \mathrm{S}$ the configurational entropic contribution per M-site, assuming an ideal solution of Ta and M' on the M-sites; $\Delta \mathrm{S}$ is given by: 


$$
\Delta \mathrm{S}=-\mathrm{wk}_{\mathrm{B}}[\mathrm{x} \ln (\mathrm{x})+(1-\mathrm{x}) \ln (1-\mathrm{x})],
$$

where $x$ is the concentration of the $M^{\prime}$ solute, $w=0.5$, and $k_{B}$ is the Boltzmann constant.

\section{Results and discussion}

\subsection{Phase assembly}

The effect of the $\mathrm{Hf}$ content in the produced $\left(\mathrm{Ta}_{1-\mathrm{x}}, \mathrm{Hf}_{\mathrm{x}}\right)_{4} \mathrm{AlC}_{3}$ ceramics was assessed by $X R D$ in terms of the relative abundance of the 413 and 211 MAX phases. Fig. 1a shows the XRD patterns of the $\left(\mathrm{Ta}_{1-\mathrm{x}}, \mathrm{Hf}_{\mathrm{x}}\right)_{4} \mathrm{AlC}_{3}$ compositions as function of the $\mathrm{Hf}$ amount, $x$, including the reference compound $\mathrm{Ta}_{4} \mathrm{AlC}_{3}(\mathrm{x}=0)$, while Fig. $2 \mathrm{a}$ shows the relative phase amounts, as determined by Rietveld refinement of the XRD patterns. The reported phase assemblies are averages deduced from XRD measurements performed on 2-3 samples per ceramic grade. Increasing the $\mathrm{Hf}$ concentration decreased linearly the amount of the 413 MAX phase, while the amount of both the 211 MAX phase and the $\left(\mathrm{Ta}_{1-\mathrm{x}}, \mathrm{Hf}_{\mathrm{x}}\right) \mathrm{C}_{\mathrm{y}}$ pseudo-binary carbides (denoted as "TaC" in Fig. 1) increased at the expense of the 413 phase, which eventually disappeared above $x=$ 0.2 , as shown in Fig. 2a. Since no XRD peaks could be attributed to Ta-Al or $\mathrm{Hf}-\mathrm{Al}$ intermetallic phases, $\left(\mathrm{Ta}_{1-\mathrm{x}}, \mathrm{Hf}_{\mathrm{x}}\right) \mathrm{C}_{\mathrm{y}}$ mixed carbides were the only detectable non-MAX phase compounds in these bulk ceramics. As the starting powder ratios targeted a 413 stoichiometry, the formation of $211 \mathrm{MAX}$ phases and pseudo-binary $\left(\mathrm{Ta}_{1-\mathrm{x}}, \mathrm{Hf}_{\mathrm{x}}\right) \mathrm{C}_{\mathrm{y}}$ carbides implies that these phases compete thermodynamically with the 413 MAX phases when $\mathrm{Hf}$ is added as a secondary solute M' element; this finding agrees with the fact that the 413 phase is predominant in the $\mathrm{Ta}_{4} \mathrm{AlC}_{3}$ ceramic, i.e., in the absence of $\mathrm{Hf}$. These results indicate that $\mathrm{Hf}$ destabilizes the 413 crystal structure configuration in favor of a 211 solid solution, and this effect becomes progressively more severe as the $\mathrm{Hf}$ concentration increases. At $\mathrm{x}=0.2$, the resulting phase assembly showed only a minor amount of the 413 MAX phase. At $x=0.25$, no 413 phase could be detected. The $211 \mathrm{Ta}_{2} \mathrm{AlC}$ phase, which is known to form at temperatures below $1500^{\circ} \mathrm{C}$ in the ternary $\mathrm{Ta}-\mathrm{Al}-\mathrm{C}$ system [10], was observed in all $\mathrm{Hf}$-containing grades, especially at higher $\mathrm{Hf}$ concentrations. While $\mathrm{Hf}_{2} \mathrm{AIC}$ is a well-documented ternary MAX compound [13], no 413 stoichiometry was ever reported in the $\mathrm{Hf}-\mathrm{Al}-\mathrm{C}$ system, which agrees with the observed instability of the $413 \mathrm{MAX}$ phase with increasing $\mathrm{Hf}$ content.

Hot pressed ceramics with the $\left(\mathrm{Ta}_{1-\mathrm{x}}, \mathrm{Nb}_{\mathrm{x}}\right)_{4} \mathrm{AlC}_{3}$ starting powder composition and $\mathrm{x}=$ $0.05,0.10,0.15,0.20$, and 0.25 were also characterized by XRD, in order to quantify the produced phases as function of the $\mathrm{Nb}$ concentration, $\mathrm{x}$. The peak-indexed XRD patterns of these ceramics are presented in Fig. 1b, including the XRD pattern of $\mathrm{Ta}_{4} \mathrm{AIC}_{3}(\mathrm{x}=0)$, while the results of phase quantification by Rietveld refinement are shown in Fig. $2 b$. Peaks of the 211 phase are clearly detected for $x=0.05$, while the major MAX phase is the 413. The lack of lattice distortion due to the same atomic radius of $\mathrm{Ta}$ and $\mathrm{Nb}$ was reflected in the absence of any shift in the diffraction peaks. Similar to the Hf-containing grades, a substantial amount of the cubic $\left(\mathrm{Ta}_{1-\mathrm{x}}, \mathrm{Nb}_{\mathrm{x}}\right) \mathrm{C}$ pseudo-binary carbides was observed with increasing $\mathrm{Nb}$ content, while the presence of sharp (111) and (200) peaks reveals that this phase formed as random solid solution.

In this system, the 211 MAX phase accounted for less than $20 \mathrm{wt} \%$ at low $\mathrm{Nb}$ concentrations, and it was almost absent at $x=0.25$. This shows that the stability of both 413 and 211 MAX phases decreases with increasing Nb content, favouring the formation of the $\left(\mathrm{Ta}_{1-x}, \mathrm{Nb}_{\mathrm{x}}\right) \mathrm{C}$ pseudo-binary carbides. In contrast to the $\mathrm{Hf}$-containing grades (Fig. 2a), the $\left(\mathrm{Ta}_{1-\mathrm{x}}, \mathrm{Nb}_{\mathrm{x}}\right)_{4} \mathrm{AlC}_{3}$ phase was converted into $\left(\mathrm{Ta}_{1-\mathrm{x}}, \mathrm{Nb}_{\mathrm{x}}\right) \mathrm{C}$ carbides 
with increasing $\mathrm{Nb}$ content (Fig. 2b). This implies that the excess $\mathrm{Al}$ can only form $\mathrm{Nb}-$ Al intermetallic phases, which were, however, not unequivocally detected by XRD, whereas $\mathrm{Al}$ in the $\mathrm{Hf}$-containing grades contributed to the formation of a 211 phase at high $x$. In all cases, no evidence of a $\beta-413$ polymorph was found, as expected from a previous study that showed that no polymorphism occurs upon hot pressing $\mathrm{Ta}_{4} \mathrm{AlC}_{3}$ below $1600^{\circ} \mathrm{C}$ [10]. $\mathrm{Al}_{2} \mathrm{O}_{3}$ could not be unequivocally identified, although its presence was revealed locally by EDS/WDS analysis, as explained in section 3.3.

For the evaluation of the thermodynamic stability of the $\left(\mathrm{Ta}_{1-\mathrm{x}}, \mathrm{Hf}_{\mathrm{x}}\right)_{2} \mathrm{AIC},\left(\mathrm{Ta}_{1-\mathrm{x}}, \mathrm{Hf}_{\mathrm{x}}\right)_{4} \mathrm{AlC}_{3}$ and $\left(\mathrm{Ta}_{1-\mathrm{x}}, \mathrm{Hf}_{\mathrm{x}}\right) \mathrm{C}$ phases by first-principle calculations, the energy of each phase was compared to an identified set of most competing phases (equilibrium simplex) in terms of the formation enthalpy, $\Delta \mathrm{H}$, using Eq. 1. Fig. 3a shows the calculated phase stability at $0 \mathrm{~K}$ for $\mathrm{M}^{\prime}=\mathrm{Hf}$, where only $\left(\mathrm{Ta}_{1-\mathrm{x}}, \mathrm{Hf}_{\mathrm{x}}\right)_{4} \mathrm{AlC}_{3}$ is found to be thermodynamically stable with a negative formation enthalpy, $\Delta \mathrm{H}$, while $\left(\mathrm{Ta}_{1-\mathrm{x}}, \mathrm{Hf}_{\mathrm{x}}\right)_{2} \mathrm{AIC}$ is the only phase with a slightly positive $\Delta \mathrm{H}$. The contribution of the configurational entropy at $1873 \mathrm{~K}\left(1600^{\circ} \mathrm{C}\right)$ to the Gibbs free energy was considered for all quaternary MAX phases and competing phases that have been modelled with disorder. The Gibbs free energy of formation, $\Delta \mathrm{G}$, of the MAX phases (calculated using Eq. 2), as compared to an identified set of the most competing phases (equilibrium simplex), is also shown in Fig. 2a. All solid solution MAX phases were found to be thermodynamically stable with $\Delta G<0$, becoming increasingly more stable with increasing $\mathrm{Hf}$ content, except for the 413 phase that shows a slight increase in $\Delta G$ at $x=0.25$. This particular result relates to the experimental evidence and the observed absence of the $\mathrm{Hf}_{4} \mathrm{AlC}_{3}$ phase. Given the small deviation in $\Delta G$ between 211 and 413 phases, no direct correlation could be established between these equilibrium approximations and the experimental findings in terms of 413 vs. 211 phase abundance; however, the $\Delta G$ of the pseudo-binary carbide phases decreases significantly with increasing $x$, thus gaining stability over the MAX phases, in agreement with experimental observations.

Fig. $3 b$ shows the calculated phase stability of the $\mathrm{Nb}$-containing phases as $\Delta \mathrm{H}$ at $0 \mathrm{~K}$ and $\Delta \mathrm{G}$ at $1873 \mathrm{~K}$. Nb-containing phases show a steady increase in $\Delta \mathrm{H}$ as function of $\mathrm{x}$ and less fluctuation when compared to $\mathrm{Hf}$-containing phases. This can be associated with the similar atomic sizes of $\mathrm{Nb}$ and $\mathrm{Ta}$, even though the $\Delta \mathrm{H}$ variation for $\mathrm{Hf}-$ containing MAX phases is still within the $5 \mathrm{meV} /$ atom range (Fig. 3a). Also in this case, all examined phases appear stable $(\Delta G<0)$ at equilibrium with decreasing $\Delta \mathrm{G}$ as $\mathrm{X}$ increases, especially for the pseudo-binary carbides that are indeed more abundant in the higher- $\mathrm{Nb}$ grades. Even though $\mathrm{Nb}-\mathrm{Al}$ intermetallics were considered competing phases, their stability was not checked individually against the other phases; hence, it is possible that their stability competes with that of the MAX phases, especially the 211 phase, with increasing $\mathrm{Nb}$ concentration, as observed during the microstructural analysis of the produced ceramics.

\subsection{Lattice parameters of $\left(\mathrm{Ta}_{1-x}, \mathrm{Hf}_{x}\right)_{4} \mathrm{AIC}_{3}$ and $\left.\left(\mathrm{Ta}_{1-x}, \mathrm{Hf}\right)_{x}\right)_{2} \mathrm{AIC}$ MAX phases}

Rietveld refinement allowed the determination of the lattice parameters $a$ and $c$ of the 413 and 211 Hf-containing MAX phases. These are shown in Figs. 4a and 4b, respectively, as function of the $\mathrm{Hf}$ content in the starting powder composition, and are compared to those of the ternary $\mathrm{Ta}_{4} \mathrm{AlC}_{3} \mathrm{MAX}$ phase compound. Both the $a$ and $c$ lattice parameters increased with increasing the $\mathrm{Hf}$ content, $\mathrm{x}$, in the $\left(\mathrm{Ta}_{1-\mathrm{x}}, \mathrm{Hf}_{\mathrm{x}}\right)_{2} \mathrm{AIC}$ and $\left(\mathrm{Ta}_{1-\mathrm{x}}, \mathrm{Hf}_{\mathrm{x}}\right)_{4} \mathrm{AlC}_{3}$ phases, due to the larger atomic radius of $\mathrm{Hf}$ as compared to $\mathrm{Ta}$. Due to the low amount of $\left(\mathrm{Ta}_{0.95}, \mathrm{Hf}_{0.05}\right)_{2} \mathrm{AlC}$ and $\left(\mathrm{Ta}_{0.80}, \mathrm{Hf}_{0.20}\right)_{4} \mathrm{AlC}_{3}$ in the produced 
ceramics, the estimated lattice parameters of these phases resulted in a rather high error margin. The measured lattice parameter values are compared to those obtained by computation in Figs. $4 a$ and $4 b$, showing a difference of $1-2 \%$ between computed and experimental values. Even though the measured lattice parameters are slightly smaller compared to the calculated ones, they both show comparable trends. In general, the generalized gradient approximation proposed by Perdew, Burke, and Ernzherhof (GGA-PBE) systematically overestimates lattice parameters, while the local-density approximation (LDA) underestimates them. Such behavior has been previously well established [37].

Despite the uncertainty ranges, the lattice parameters increased linearly with the $\mathrm{Hf}$ content (Fig. 4), following Vegard's law [38]. The observed trend seems to indicate, however, that the lattice parameters of the 211 phase deviate from linearity at higher $\mathrm{Hf}$ concentration $(x=0.25)$, after having reached a maximum at $x=0.2$. A similar trend is observed for the 413 phase, despite the large error stemming from the low phase content at $x=0.25$. Such deviation from linearity can most likely be associated with a Hf solubility limit in these MAX phases at around $x=0.2$.

\subsection{Microstructure}

In agreement with the XRD phase quantification results, SEM analysis of metallographic cross-sections of the bulk ceramics revealed the presence of MAX phase grains and binary carbide regions, as shown in Fig. 5a for TH10 and Fig. 5b for $\mathrm{TH} 25$, respectively. In the low-Hf TH10 grade, MAX phase lamellae are visible in the backscattered electron (BSE) mode (Fig. 5a). The lamellar crystal habit assumed by the faceted MAX phase grains reflects the high aspect ratio $(c / a)$ of the lattice parameters, and results from the much faster crystal growth parallel to the basal planes than perpendicular to them [39]. The 413 MAX phase grains appear brighter than the 211 ones in the BSE mode, due to a higher average atomic number. The 413 grains have an average length of $\sim 10 \mu \mathrm{m}$ and a strongly varying thickness. In particular, a fraction of very thin 413 grains are present within the 211 phase-rich areas. The 211 phase grains are generally shorter, with lengths not exceeding $5 \mu \mathrm{m}$ and typical aspect ratios of about 3:1. The observed difference in the grain size of the two MAX phases could be attributed to differences in the driving force for crystal growth, which is in turn associated with the relative undercooling below the solidification temperature of each one of the 2 phases; typically, higher undercooling means higher driving force for nucleation and growth [38]. Since the 413 crystal structure is stable at higher temperatures than the 211 , the growth of 413 grains is expected to be faster than the growth of 211 grains at the sintering temperature $\left(1550^{\circ} \mathrm{C}\right)$, forming 413 grains with higher aspect ratios when compared to the 211 grains.

In the higher $\mathrm{Hf}$ TH25 grade, only 211 grains are observed along finer-grained binary carbide phases (Fig. 5b), in accordance with the XRD results. In both grades, $\mathrm{Al}_{2} \mathrm{O}_{3}$ grains were detected (Figs. $5 a$ and $5 b$ ), as it is often observed in Al-containing MAX phases. The formation of alumina is generally caused by a slight oxidation of the starting powder, in combination with an imperfect vacuum during reaction sintering, both of which supply oxygen to the powder mixture. The study of the fracture surface of the TH25 grade revealed a mixture of MAX phase lamellae and fine-grained binary carbides (Fig. 5c).

Figs. $5 d$ and $5 e$ show the microstructure of the TN10 and TN25 grade, respectively, indicating that the 413 grains in TN10 exhibit variation in the Nb distribution, as reflected in the non-uniform compositional contrast and confirmed by EDS point 
analyses. The TN25 grade contained minor amounts of $\left(\mathrm{Ta}_{0.75}, \mathrm{Nb}_{0.25}\right) \mathrm{Al}_{2}$ intermetallics between the MAX phase grains. In all $\mathrm{Nb}$-containing materials, equiaxed $\mathrm{Nb}-\mathrm{Al}$ intermetallic grains (10-100 $\mu \mathrm{m}$ in diameter) were detected, as may be seen on the fracture surface of grade TN25 (Fig. 5f), as well as in Fig. 6a, which depicts a Nb-Al intermetallic grain enveloped by a MAX phase grain in the TN10 grade. EDS point analysis estimated the composition of this intermetallic as $\mathrm{Al}_{0.8} \mathrm{Nb}_{0.2}$, which is close to the $\mathrm{Al}_{3} \mathrm{Nb}$ phase in the $\mathrm{Nb}-\mathrm{Al}$ phase diagram [40]. As shown in Figs. 6e and 6f, the fraction of $\mathrm{Nb}-\mathrm{Al}$ intermetallics is lower in TN10 than in TN25. The presence of Al-rich $\mathrm{Nb}-\mathrm{Al}$ intermetallics in the $\mathrm{Nb}$-containing ceramics indicates that the stabilization of the 413 and 211 MAX phases at the specific processing conditions becomes progressively more difficult as the $\mathrm{Nb}$ content increases. $\mathrm{Al}_{2} \mathrm{O}_{3}$ grains formed also in the $\mathrm{Nb}$ containing ceramics, as shown in Figs. $5 d, 5 e, 5 f, 6 a$, and $6 b$.

WDS elemental mapping was performed on metallographic cross-sections of the TH10 and TH25 grades as shown in Figs. 7 and 8, respectively. In agreement with XRD results, the main phases identified in TH10 were the 413 and 211 MAX phases (Fig. 7). The 413 phase appears brighter than the 211 phase, due to its lower Al and higher $\mathrm{C}$ contents. Within the 211 MAX phase regions, the growth of isolated, thin 413 laths (similar to $\mathrm{TH} 10$, see Fig. 5a) with lower relative Hf concentration was observed. In the $\mathrm{TH} 25$ grade (Fig. 8), a wide region of $\left(\mathrm{Ta}_{1-\mathrm{x}}, \mathrm{Hf}_{\mathrm{x}}\right) \mathrm{C}_{\mathrm{y}}$ pseudo-binary carbides was observed, as indicated by the complete absence of Al. Hf was non-uniformly dispersed in the $\left(\mathrm{Ta}_{1-\mathrm{x}}, \mathrm{Hf}_{\mathrm{x}}\right) \mathrm{C}_{\mathrm{y}}$ regions, in agreement with the fact that the $\mathrm{TaC}-\mathrm{HfC}$ system has a miscibility gap [9].

Additionally, elemental mapping showed the prevalence of the 211 MAX phase, where the central area contained comparatively less $\mathrm{Hf}$ and more $\mathrm{Ta}$ than the rest of the phase. Point analysis in this area indicated the following composition: $\left(\mathrm{Ta}_{0.86}, \mathrm{Hf}_{0.14}\right)_{4} \mathrm{AlC}_{3}$. The distribution of $\mathrm{Hf}$ was not entirely homogeneous, as shown from the elemental analysis at select points. However, in both $\mathrm{TH} 10$ and $\mathrm{TH} 25$ grades, the $\mathrm{Hf}$ concentration averaged at the initially targeted $\mathrm{x}$. Intermetallic phases, normally found between the MAX phase laths, could not be observed, in agreement with XRD. This is most likely due to the comparatively more favorable formation of $\mathrm{Al}_{2} \mathrm{O}_{3}$ from the excess Al. Al, Ta and Nb EDS elemental maps of an area in TN10 (Fig. 6a) are shown in Figs. 6b, 6c, and 6d, respectively.

STEM imaging was performed on FIB thin foils extracted from 413 and 211 MAX phase grains in both TH10 and TH25 grades. The 211 phase is shown in Fig. 9a for $x=0.1$ and in Fig. 9b for $x=0.25$, whereas the 413 phase is shown in Fig. 9c for $x=0.1$, while a hybrid structure is shown in Fig. 9d for $x=0.25$. All structures were observed along the $<11 \overline{2} 0>$ zone axis. The contrast allows to clearly distinguish the single rows of dark Al atoms arranged along the single-atom-thick A-layers of the MAX phase lattice and between the bright layers of $\mathrm{Ta}$ and $\mathrm{Hf}$ atoms. As result of the increased average $c$ parameter caused by the presence of $\mathrm{Hf}$ atoms in the $\mathrm{M}$ sub-lattice, the mismatch in interplanar spacing can be directly seen by comparing a small sequence of parallel Alayers at identical magnifications. This is shown in Figs. 9a and 9b for the 211 phase in the $\mathrm{TH} 10$ and $\mathrm{TH} 25$ grade, respectively.

Further proof of the solubility of $\mathrm{Hf}$ in the MAX phase lattice was provided by TEM/EDS elemental maps showing the distribution of solute elements in the MX sheets, as may be seen in Figs. 9e and 9 for $x=0.1$ and 0.25 , respectively. Fig. 9f shows an ABAB sequence of mixed 413 and 615 structures as well, similar to what was observed in TaAl-C MAX phases [11]. The maps show a superimposed EDS signal of homogeneously 
mixed $\mathrm{Ta}$ and $\mathrm{Hf}$ within the MX sheets, indicating the uniform distribution of these two elements in the MX layers.

STEM images of 413 MAX phase atomic stacks in the TN10 and TN25 grades are shown in Figs. $9 \mathrm{~g}$ and $9 \mathrm{~h}$, respectively. Similar to the TH25 grade, defects in the 413 structure were found in TN25 with occasional alternating 413-211 stacking sequences (Fig. 9h), however, the 413 MAX phase conserves a regular ABCD stacking. This points out the non-uniformity in the number of atomic layers introduced in the MX sheets by higher $\mathrm{Nb}$ concentrations. TEM/EDS elemental mapping revealed a homogeneous distribution of $\mathrm{Ta}$ and $\mathrm{Nb}$ in the MX sheets, alternated by Al layers, as shown in Figs. 9i and 9j for TN10 and TN25, respectively. Quite interestingly, TEM analysis did not reveal the presence of the $\beta-413$ polymorph.

\subsection{Effects of Sn addition}

The $\left(\mathrm{Ta}_{0.75}, \mathrm{Hf}_{0.25}\right){ }_{4} \mathrm{AlC}_{3}$ starting composition, hot pressed at $1550^{\circ} \mathrm{C}$, contained $63 \mathrm{wt} \%$ of the 211 MAX phase, $37 \mathrm{wt} \%$ of the $\left(\mathrm{Ta}_{1-\mathrm{x}}, \mathrm{Hf}_{\mathrm{x}}\right) \mathrm{C}_{\mathrm{y}}$ pseudo-binary phase, and only a very small amount (below the XRD detection limit) of the 413 MAX phase (Fig. 1). In order to increase the amount of the 413 MAX phase, $50 \%$ of the Al content was substituted for $\mathrm{Sn}$, in analogy with prior studies on the synthesis of phase-pure $(\mathrm{Zr}, \mathrm{Nb})_{2}(\mathrm{Al}, \mathrm{Sn}) \mathrm{C}[41]$ and $(\mathrm{Zr}, \mathrm{Ti})_{2}(\mathrm{Al}, \mathrm{Sn}) \mathrm{C}[20] \mathrm{MAX}$ phase ceramics. In those studies, the enhanced stability of the 211 MAX phases over the competing binary phases (carbides, intermetallics) was associated with the trigonal prism distortion parameter and the relative size of the $M$ and $A$ atoms in the $M_{6} A$ prism [42]. These studies demonstrated experimentally that highly phase-pure bulk MAX phase ceramics can be produced by forming solid solutions on both $M$ and $A$ sites [42]. Apart from giving a comprehensive review of the importance of steric effects in MAX phase lattice distortions, one of these studies demonstrated that a reduced prismatic distortion in the crystal lattice due to smaller differences in the $M$ and $A$ atomic sizes could ensure the synthesis of phase-pure $\left(\mathrm{Zr}_{0.8}, \mathrm{Nb}_{0.2}\right)_{2}\left(\mathrm{Al}_{0.5}, \mathrm{Sn}_{0.5}\right) \mathrm{C}$ MAX phase ceramics [41].

In this work, the same approach was adopted to increase the fraction of the 413 phase in the ceramic with the least 413 amount, i.e., the TH25 grade. More precisely, Sn (atomic radius: $145 \mathrm{pm}$ ) [42] was replaced $50 \%$ of $\mathrm{Al}$ (atomic radius: $125 \mathrm{pm}$ ) [42] to compensate for the increase in average $M$ atomic size caused by the partial replacement of $\mathrm{Ta}$ by $\mathrm{Hf}$ (atomic radii: $145 \mathrm{pm}$ and $155 \mathrm{pm}$, respectively) [42]. The $\left(\mathrm{Ta}_{0.75}, \mathrm{Hf}_{0.25}\right)_{4}\left(\mathrm{Al}_{0.5}, \mathrm{Sn}_{0.5}\right) \mathrm{C}_{3}$ MAX phase double solid solution ("THS25" grade), processed under exactly the same conditions as the TH25 grade, contained $62.8 \mathrm{wt} \%$ of the 413 phase as compared to the negligible 413 amount in the TH25 grade. The same approach was also applied on the TN25 grade, where a higher 413 MAX phase content was targeted by synthesising the $\left(\mathrm{Ta}_{0.75}, \mathrm{Nb}_{0.25}\right)_{4}\left(\mathrm{Al}_{0.5}, \mathrm{Sn}_{0.5}\right) \mathrm{C}_{3}$ double solid solution ("TNS25" ceramic).

The obtained XRD patterns are shown in Fig. 10a for the Hf-containing ceramics and Fig. $10 \mathrm{~b}$ for the $\mathrm{Nb}$-containing ceramics. Table 1 summarizes the phase compositions of these ceramic grades as determined by Rietveld refinement. In the THS25 grade, no 211 MAX phase was observed as a result of the Sn addition, in contrast with the TH25 grade, where its formation was favored over that of the 413 phase. At $x=25 \%$, the addition of $S n$ as lattice distortion modifier reduced both lattice parameters of the 413 MAX phase to $a=3.11(6) \AA$ and $c=24.10(1) \AA$, respectively; these values coincide with those of the $\mathrm{Ta}_{4} \mathrm{AlC}_{3}$ ternary compound [10], confirming the reduction in lattice distortion. Therefore, the Sn addition promoted the formation of the 413 MAX phase as intended; however, $39.2 \mathrm{wt} \%$ of the $\left(\mathrm{Ta}_{1-\mathrm{x}}, \mathrm{Hf}_{\mathrm{x}}\right) \mathrm{C}_{\mathrm{y}}$ pseudo-binary carbide was still 
present in the produced ceramic. It is also worthwhile mentioning that the Sn addition to the $\left(\mathrm{Ta}_{0.75}, \mathrm{Hf}_{0.25}\right)_{4} \mathrm{AlC}_{3}$ system stabilized only the 413 phase, while completely suppressing the formation of the 211 MAX phase.

In the TNS25 grade, $\left(\mathrm{Ta}_{0.75}, \mathrm{Nb}_{0.25}\right)_{4}\left(\mathrm{Al}_{0.5}, \mathrm{Sn}_{0.5}\right) \mathrm{C}_{3}$ and $\left(\mathrm{Ta}_{0.75}, \mathrm{Nb}_{0.25}\right)_{2}\left(\mathrm{Al}_{0.5}, \mathrm{Sn}_{0.5}\right) \mathrm{C}$ MAX phase double solid solutions formed, substantially increasing the overall MAX phase content as compared to the TN25 grade. Due to the coinciding atomic radii of $\mathrm{Nb}$ and $\mathrm{Ta}(145 \mathrm{pm})$ [42], the incorporation of $\mathrm{Nb}$ in the MAX phase crystal lattice did not produce a measurable lattice distortion. For this reason, the loss of stability of the 413 MAX phase at higher $\mathrm{Nb}$ concentrations in the quaternary phases should not be explained in terms of lattice distortion, but rather in terms of a reduction in the thermodynamic stability of the MAX phases as compared to that of the binary carbide and intermetallic phases. Even though no first-principle studies were done for these double solid solutions, the results suggest that adding Sn increases the stability of both 413 and 211 phases at the cost of the $\left(\mathrm{Ta}_{1-\mathrm{x}}, \mathrm{Nb}_{\mathrm{x}}\right) \mathrm{C}_{\mathrm{y}}$ pseudo-binary carbide, the content of which was substantially decreased from $45.1 \mathrm{wt} \%$ in the TN25 grade to $5.8 \mathrm{wt} \%$ in the TNS25 grade.

Figs. 11a and 11b show the microstructure of the THS25 and TNS25 double solid solution grade, respectively: MAX phase lamellae and equiaxed pseudo-binary carbide grains were observed, similar to the respective grades without $\mathrm{Sn}$ and those with lower $\mathrm{M}^{\prime}$ solute concentrations. TNS25 also contained an intergranular $\mathrm{Ta}-\mathrm{Nb}-\mathrm{Al}-\mathrm{Sn}$ intermetallic phase, the formation of which was confirmed by EDS. However, the formation of large $\mathrm{Al}-\mathrm{Nb}$ intermetallic grains could not be observed, as in the case of the TN25 grade.

In order to further increase the purity of MAX phase ceramics in the Ta-Hf-Nb-Al-C system by the addition of a second solute element on the A site, a systematic study must be performed to define the optimum stoichiometry and corresponding lattice distortion parameters, as was previously done for Zr-based 211 MAX phase solid solutions [41].

\section{Conclusions}

$\left(\mathrm{Ta}_{1-\mathrm{x}}, \mathrm{Hf}_{\mathrm{x}}\right)_{4} \mathrm{AlC}_{3},\left(\mathrm{Ta}_{1-\mathrm{x}}, \mathrm{Nb}_{\mathrm{x}}\right)_{4} \mathrm{AlC}_{3},\left(\mathrm{Ta}_{1-\mathrm{x}}, \mathrm{Hf}_{\mathrm{x}}\right)_{2} \mathrm{AIC}$ and $\left(\mathrm{Ta}_{1-\mathrm{x}}, \mathrm{Nb}_{\mathrm{x}}\right)_{2} \mathrm{AIC}$ MAX phase solid solutions with $\mathrm{x}=0.05,0.1,0.15,0.2$ and 0.25 were synthesized by reactive hot pressing of $\mathrm{Ta}_{2} \mathrm{H}, \mathrm{HfH}_{2}, \mathrm{NbH}_{0.89}, \mathrm{Al}$ and $\mathrm{C}$ powder mixtures.

The stability of the 413 compound $\left(\mathrm{Ta}_{1-\mathrm{x}}, \mathrm{Hf}_{\mathrm{x}}\right)_{4} \mathrm{AlC}_{3}$ decreased with increasing $\mathrm{Hf}$ content, due to the crystal lattice distortion by the introduction of the larger $\mathrm{Hf}$ atom, and in favor of the 211 compound $\left(\mathrm{Ta}_{1-\mathrm{x}}, \mathrm{Hf}_{\mathrm{x}}\right)_{2} \mathrm{AlC}$ and $\left(\mathrm{Ta}_{1-\mathrm{x}}, \mathrm{Hf}_{\mathrm{x}}\right) \mathrm{C}_{\mathrm{y}}$ pseudo-binary carbides. The estimated solubility limit for $\mathrm{Hf}$ in the 413 and 211 MAX phases was around $x=0.2$. The 413 phase content exceeded $80 \mathrm{wt} \%$ only in ceramic grades with low amounts of solute $(x=0.05)$.

The stability of the $\left(\mathrm{Ta}_{1-\mathrm{x}}, \mathrm{Nb}_{\mathrm{x}}\right)_{4} \mathrm{AlC}_{3}$ and $\left(\mathrm{Ta}_{1-\mathrm{x}}, \mathrm{Nb}_{\mathrm{x}}\right)_{2} \mathrm{AIC}$ MAX phases decreased with increasing $\mathrm{Nb}$ content, presumably due to the thermodynamically more stable $\left(\mathrm{Ta}_{1}\right.$ $\left.{ }_{x}, \mathrm{Nb}_{x}\right) \mathrm{C}_{y}$ pseudo-binary carbides and $\mathrm{Nb}-\mathrm{Al}$ intermetallics at higher $\mathrm{Nb}$ contents. Substitution of $50 \%$ of the Al on the A site for Sn increased the stability of the $\left(\mathrm{Ta}_{0.75}, \mathrm{Hf}_{0.25}\right)_{4}\left(\mathrm{Al}_{0.5}, \mathrm{Sn}_{0.5}\right) \mathrm{C}_{3}$ MAX phase in equilibrium with $(\mathrm{Ta}, \mathrm{Hf}) \mathrm{C}$ pseudo-binary carbides, whereas no $\left(\mathrm{Ta}_{0.75}, \mathrm{Hf}_{0.25}\right)_{2}\left(\mathrm{Al}_{0.5}, \mathrm{Sn}_{0.5}\right) \mathrm{C}$ MAX phase was observed. Substitution of $50 \%$ of the Al for $\mathrm{Sn}$ in the $\left(\mathrm{Ta}_{0.75}, \mathrm{Hf}_{0.25}\right)_{4} \mathrm{AlC}_{3}$ system increased the stability of both $\left(\mathrm{Ta}_{0.75}, \mathrm{Nb}_{0.25}\right)_{4}\left(\mathrm{Al}_{0.5}, \mathrm{Sn}_{0.5}\right) \mathrm{C}_{3}$ and $\left(\mathrm{Ta}_{0.75}, \mathrm{Nb}_{0.25}\right)_{2}\left(\mathrm{Al}_{0.5}, \mathrm{Sn}_{0.5}\right) \mathrm{C}$ MAX phases, limiting the content of the $(\mathrm{Ta}, \mathrm{Nb}) \mathrm{C}$ pseudo-binary carbides to $\sim 6 \mathrm{wt} \%$. 


\section{Acknowledgements}

M. Griseri thanks SCK·CEN for his PhD fellowship through the ISOL@MYRRHA project. Additional acknowledgements are extended to colleagues from the Dept. of Materials Engineering of the KU Leuven for their support, with special mention to former colleague Dr. Thomas Lapauw for the inspiration stemming from his pioneering work on the MAX phases. Many thanks to Prof. Thierry Cabioc'h from the University of Poitiers, France, for advice on XRD analysis. The authors acknowledge the Hercules Foundation under Project AKUL/1319 (CombiS(T)EM). The calculations were carried out using supercomputer resources provided by the Swedish National Infrastructure for Computing (SNIC) at the National Supercomputer Centre (NSC) and the PDC Center for High Performance Computing. The authors finally acknowledge the Knut and Alice Wallenberg Foundation for support of the electron microscope laboratory at Linköping University.

\section{References}

[1] M.W. Barsoum, MAX Phases, Properties of Machinable Ternary Carbides and Nitrides, Wiley-VCH, 2013.

[2] M. Sokol, V. Natu, S. Kota, M.W. Barsoum, On the Chemical Diversity of the MAX Phases, Trends Chem. 1 (2019) 210-223. doi:10.1016/j.trechm.2019.02.016.

[3] O. Cedillos-Barraza, D. Manara, K. Boboridis, T. Watkins, S. Grasso, D.D. Jayaseelan, R.J.M. Konings, M.J. Reece, W.E. Lee, Investigating the highest melting temperature materials: A laser melting study of the TaC-HfC system, Sci. Rep. 6 (2016) 37962. doi:10.1038/srep37962.

[4] Q.-J. Hong, A. van de Walle, Prediction of the material with highest known melting point from ab initio molecular dynamics calculations, Phys. Rev. B. 92 (2015) 20104. doi:10.1103/PhysRevB.92.020104.

[5] M. Borge, Y. Kadi, ISOLDE at CERN, Nucl. Phys. News. 26 (2016) 6-13. doi:10.1080/10619127.2016.1249214.

[6] R. dos Santos Augusto, L. Buehler, Z. Lawson, S. Marzari, M. Stachura, T. Stora, CERN-MEDICIS (Medical Isotopes Collected from ISOLDE): A New Facility, Appl. Sci. 4 (2014) 265-281. doi:10.3390/app4020265.

[7] J.P. Ramos, Thick solid targets for the production and online release of radioisotopes: The importance of the material characteristics - A review, Nucl. Instruments Methods Phys. Res. Sect. B Beam Interact. with Mater. Atoms. (2019). doi:https://doi.org/10.1016/j.nimb.2019.05.045.

[8] O. Cedillos-Barraza, S. Grasso, N. Al Nasiri, D.D. Jayaseelan, M.J. Reece, W.E. Lee, Sintering behaviour, solid solution formation and characterisation of $\mathrm{TaC}$, $\mathrm{HfC}$ and TaC-HfC fabricated by spark plasma sintering, J. Eur. Ceram. Soc. 36 (2016) 1539-1548. doi:10.1016/j.jeurceramsoc.2016.02.009.

[9] A.I. Gusev, A.A. Rempel, A.J. Magerl, Disorder and order in strongly nonstiochiometric Compounds, 2001. doi:10.1007/978-3-662-04582-4.

[10] M. Griseri, B. Tunca, T. Lapauw, S. Huang, L. Popescu, M.W. Barsoum, K. Lambrinou, J. Vleugels, Synthesis, properties and thermal decomposition of the $\mathrm{Ta}_{4} \mathrm{AlC}_{3}$ MAX phase, J. Eur. Ceram. Soc. (2019). doi:10.1016/j.jeurceramsoc.2019.04.021.

[11] Z. Lin, M. Zhuo, Y. Zhou, M. Li, J. Wang, Microstructures and theoretical bulk modulus of layered ternary tantalum aluminum carbides, J. Am. Ceram. Soc. 89 (2006) 3765-3769. doi:10.1111/j.1551-2916.2006.01303.x.

[12] C. Hu, Z. Lin, L. He, Y. Bao, J. Wang, M. Li, Y. Zhou, Physical and mechanical 
properties of bulk $\mathrm{Ta}_{4} \mathrm{AlC}_{3}$ ceramic prepared by an in situ reaction synthesis/hotpressing method, J. Am. Ceram. Soc. 90 (2007) 2542-2548. doi:10.1111/j.15512916.2007.01804.x.

[13] T. Lapauw, B. Tunca, T. Cabioc'h, J. Lu, P. O. Å. Persson, K. Lambrinou, J. Vleugels, Synthesis of MAX Phases in the Hf-Al-C System, Inorg. Chem. 56 (2017) 3489-3498. doi:10.1021/acs.inorgchem.6b03057.

[14] J. Schuster, H. Nowotny, Investigations of the Ternary Systems (Zr,Hf,Nb,Ta)-Al$C$ and Studies on Complex Carbides, Zeitschrift Fuer Met. Res. Adv. Tech. (1980) 341-364.

[15] T. Lapauw, D. Tytko, K. Vanmeensel, S. Huang, P.P. Choi, D. Raabe, E.N. Caspi, O. Ozeri, M. To Baben, J.M. Schneider, K. Lambrinou, J. Vleugels, $\left(\mathrm{Nb}_{x}, \mathrm{Zr}_{1-\mathrm{x}}\right)_{4} \mathrm{AlC}_{3} \mathrm{MAX}$ Phase Solid Solutions: Processing, Mechanical Properties, and Density Functional Theory Calculations, Inorg. Chem. 55 (2016) 5445-5452. doi:10.1021/acs.inorgchem.6b00484.

[16] J. Halim, J. Palisaitis, J. Lu, J. Thörnberg, E.J. Moon, M. Precner, P. Eklund, P.O.A. Persson, M.W. Barsoum, J. Rosen, Synthesis of Two-Dimensional $\mathrm{Nb}_{1.33} \mathrm{C}$ (MXene) with Randomly Distributed Vacancies by Etching of the Quaternary Solid Solution (Nb2/3Sc1/3)2AIC MAX Phase, ACS Appl. Nano Mater. 1 (2018) 2455-2460. doi:10.1021/acsanm.8b00332.

[17] J. Yang, M. Naguib, M. Ghidiu, L.-M. Pan, J. Gu, J. Nanda, J. Halim, Y. Gogotsi, M.W. Barsoum, Two-Dimensional Nb-Based $\mathrm{M}_{4} \mathrm{C}_{3}$ Solid Solutions (MXenes), J. Am. Ceram. Soc. 99 (2016) 660-666. doi:10.1111/jace.13922.

[18] J. Gu, L. Pan, J. Yang, L. Yu, H. Zhang, W. Zou, C. Xu, C. Hu, T. Qiu, Mechanical properties and oxidation behavior of Ti-doped $\mathrm{Nb}_{4} \mathrm{AlC}_{3}$, J. Eur. Ceram. Soc. 36 (2015). doi:10.1016/j.jeurceramsoc.2015.10.023.

[19] T. Lapauw, B. Tunca, D. Potashnikov, A. Pesach, O. Ozeri, J. Vleugels, K. Lambrinou, The double solid solution $(\mathrm{Zr}, \mathrm{Nb})_{2}(\mathrm{Al}, \mathrm{Sn}) \mathrm{C}$ MAX phase: a steric stability approach, Sci. Rep. 8 (2018) 1-13. doi:10.1038/s41598-018-31271-2.

[20] B. Tunca, T. Lapauw, R. Delville, D.R. Neuville, L. Hennet, D. Thiaudière, T. Ouisse, J. Hadermann, J. Vleugels, K. Lambrinou, Synthesis and Characterization of Double Solid Solution $(\mathrm{Zr}, \mathrm{Ti})_{2}(\mathrm{Al}, \mathrm{Sn}) \mathrm{C}$ MAX Phase Ceramics, Inorg. Chem. 2 (2019). doi:10.1021/acs.inorgchem.9b00065.

[21] L. Lutterotti, S. Matthies, H.R. Wenk, MAUD: a friendly Java program for material analysis using diffraction, IUCr Newsl. CPD. 21 (1999).

[22] G. Kresse, J. Furthmüller, Efficient iterative schemes for ab initio total-energy calculations using a plane-wave basis set, Phys. Rev. B. 54 (1996) 1116911186. doi:10.1103/PhysRevB.54.11169.

[23] J.P. Perdew, K. Burke, M. Ernzerhof, Generalized Gradient Approximation Made Simple, Phys. Rev. Lett. $77 \quad$ (1996) 3865-3868. doi:10.1103/PhysRevLett.77.3865.

[24] H.J. Monkhorst, J.D. Pack, Special points for Brillouin-zone integrations, Phys. Rev. B. 13 (1976) 5188-5192. doi:10.1103/PhysRevB.13.5188.

[25] A. Zunger, S.-H. Wei, L.G. Ferreira, J.E. Bernard, Special quasirandom structures, Phys. Rev. Lett. 65 (1990) 353-356. doi:10.1103/PhysRevLett.65.353.

[26] A. Van De Walle, P. Tiwary, M. De Jong, D.L. Olmsted, M. Asta, A. Dick, D. Shin, Y. Wang, L.Q. Chen, Z.K. Liu, Efficient stochastic generation of special quasirandom structures, Calphad Comput. Coupling Phase Diagrams Thermochem. 42 (2013) 13-18. doi:10.1016/j.calphad.2013.06.006.

[27] M. Dahlqvist, B. Alling, I.A. Abrikosov, J. Rosén, Phase stability of Ti2AIC upon 
oxygen incorporation: A first-principles investigation, Phys. Rev. B. 81 (2010) 24111. https://link.aps.org/doi/10.1103/PhysRevB.81.024111.

[28] M. Dahlqvist, B. Alling, J. Rosén, Stability trends of MAX phases from first principles, Phys. Rev. B. 81 (2010) 220102.

[29] A. Thore, M. Dahlqvist, B. Alling, J. Rosén, First-principles calculations of the electronic, vibrational, and elastic properties of the magnetic laminate $\mathrm{Mn}_{2} \mathrm{GaC}$, J. Appl. Phys. 116 (2014) 103511. doi:10.1063/1.4894411.

[30] R. Meshkian, Q. Tao, M. Dahlqvist, J. Lu, L. Hultman, J. Rosen, Theoretical stability and materials synthesis of a chemically ordered MAX phase, Mo2ScAIC2, and its two-dimensional derivate $\mathrm{Mo}_{2} \mathrm{ScC}_{2}$ MXene, Acta Mater. 125 (2017) 476-480. doi:10.1016/j.actamat.2016.12.008.

[31] M. Dahlqvist, J. Lu, R. Meshkian, Q. Tao, L. Hultman, J. Rosén, Prediction and synthesis of a family of atomic laminate phases with Kagomé-like and in-plane chemical ordering, 2017. doi:10.1126/sciadv.1700642.

[32] B. Anasori, M. Dahlqvist, J. Halim, E.J. Moon, J. Lu, B.C. Hosler, E.N. Caspi, S.J. May, L. Hultman, P. Eklund, J. Rosén, M.W. Barsoum, Experimental and theoretical characterization of ordered MAX phases Mo2TiAIC2 and Mo2Ti2AIC3, J. Appl. Phys. 118 (2015) 94304. doi:10.1063/1.4929640.

[33] A.S. Ingason, A. Petruhins, M. Dahlqvist, F. Magnus, A. Mockute, B. Alling, L. Hultman, I.A. Abrikosov, P.O.Å. Persson, J. Rosen, A Nanolaminated Magnetic Phase: $\quad \mathrm{Mn}_{2} \mathrm{GaC}$, Mater. Res. Lett. 2 (2014) 89-93. doi:10.1080/21663831.2013.865105.

[34] P. Eklund, M. Dahlqvist, O. Tengstrand, L. Hultman, J. Lu, N. Nedfors, U. Jansson, J. Rosén, Discovery of the Ternary Nanolaminated Compound $\mathrm{Nb}_{2} \mathrm{GeC}$ by a Systematic Theoretical-Experimental Approach, Phys. Rev. Lett. 109 (2012) 35502. doi:10.1103/PhysRevLett.109.035502.

[35] M. Dahlqvist, B. Alling, I.A. Abrikosov, J. Rosen, Magnetic nanoscale laminates with tunable exchange coupling from first principles, Phys. Rev. B. 84 (2011) 220403. doi:10.1103/PhysRevB.84.220403.

[36] A.S. Ingason, A. Mockute, M. Dahlqvist, F. Magnus, S. Olafsson, U.B. Arnalds, B. Alling, I.A. Abrikosov, B. Hjörvarsson, P.O.A. Persson, J. Rosen, Magnetic Self-Organized Atomic Laminate from First Principles and Thin Film Synthesis, Phys. Rev. Lett. 110 (2013) 195502. doi:10.1103/PhysRevLett.110.195502.

[37] L. He, F. Liu, G. Hautier, M.J.T. Oliveira, M.A.L. Marques, F.D. Vila, J.J. Rehr, G.-M. Rignanese, A. Zhou, Accuracy of generalized gradient approximation functionals for density-functional perturbation theory calculations, Phys. Rev. B. 89 (2014) 64305. doi:10.1103/PhysRevB.89.064305.

[38] L. Vegard, Die Konstitution der Mischkristalle und die Raumfüllung der Atome, Zeitschrift Für Phys. 5 (1921) 17-26. doi:10.1007/BF01349680.

[39] W. Kurz, D.J. Fisher, Fundamentals of Solidification, 4th ed., Trans Tech Publications, Zurich, 1998.

[40] \& E.C. Ansara, I., Dinsdale, A. T., Rand, M. H., European Cooperation in Scientific and Technical Research., Thermochemical database for light metal alloys, Luxembourg, 1998.

[41] T. Lapauw, B. Tunca, D. Potashnikov, A. Pesach, O. Ozeri, J. Vleugels, K. Lambrinou, The double solid solution $(\mathrm{Zr}, \mathrm{Nb})_{2}(\mathrm{Al}, \mathrm{Sn}) \mathrm{C}$ MAX phase: a steric stability approach, Sci. Rep. 8 (2018) 1-13. doi:10.1038/s41598-018-31271-2.

[42] J.C. Slater, Atomic radii in crystals, J. Chem. Phys. 41 (1964) 3199-3204. doi:10.1063/1.1725697. 

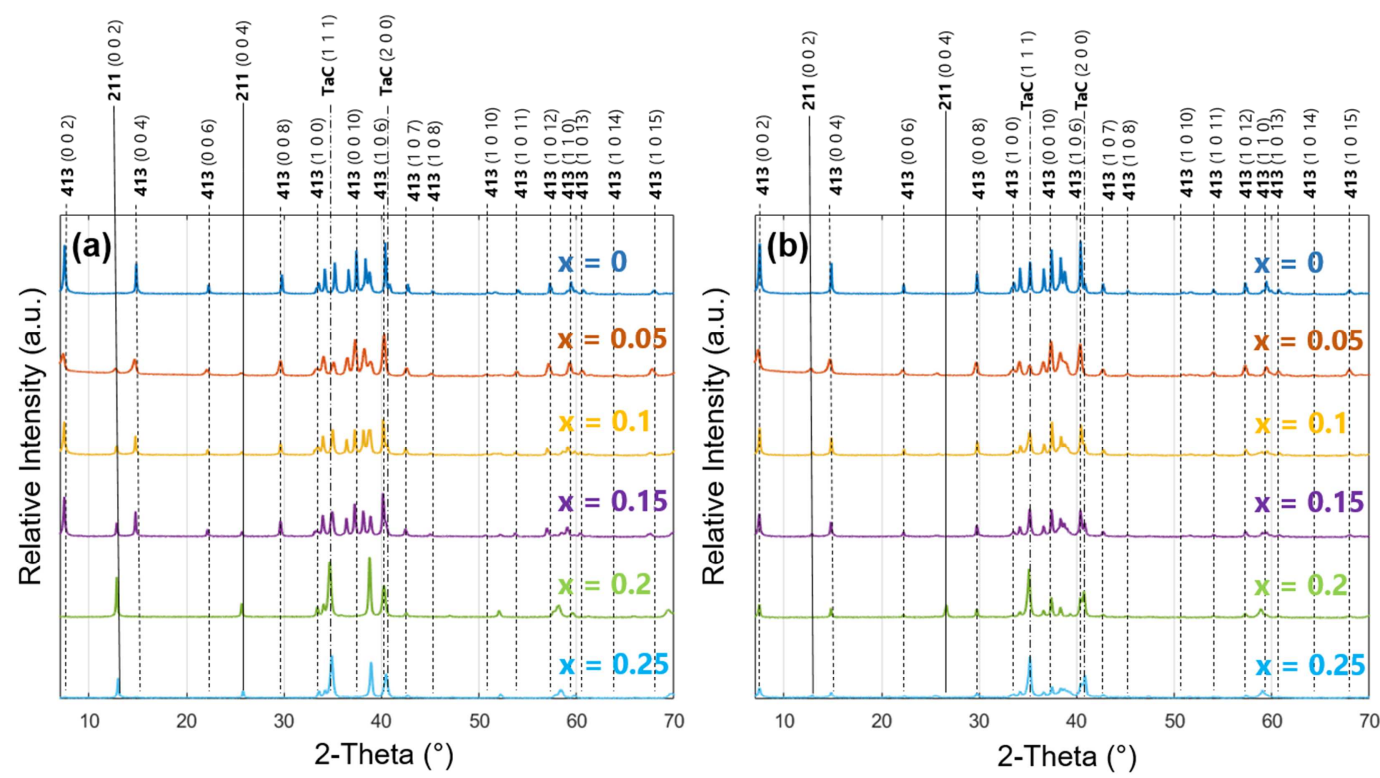

Fig. 1. XRD patterns of reaction hot pressed ceramics with (a) $\left(\mathrm{Ta}_{1-\mathrm{x}}, \mathrm{Hf}_{\mathrm{x}}\right)_{4} \mathrm{AlC}_{3}$, and (b) $\left(\mathrm{Ta}_{1-x}, \mathrm{Nb}_{\mathrm{x}}\right)_{4} \mathrm{AlC}_{3}$ starting powder compositions, for different $\mathrm{x}$ contents of $\mathrm{Hf}$ and $\mathrm{Nb}$.

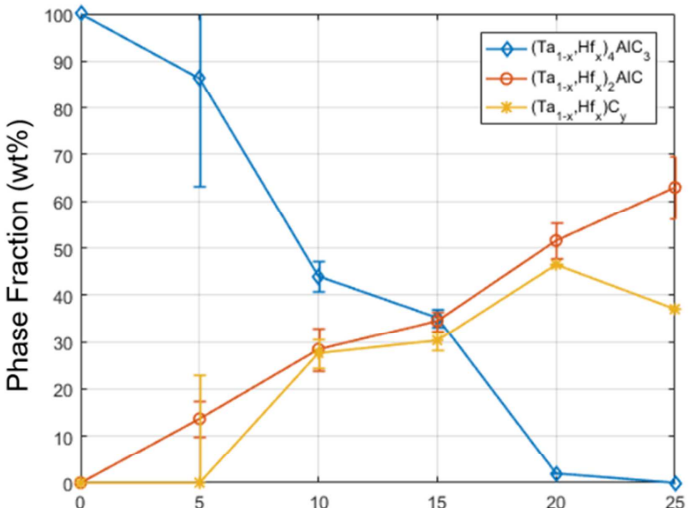

(a)

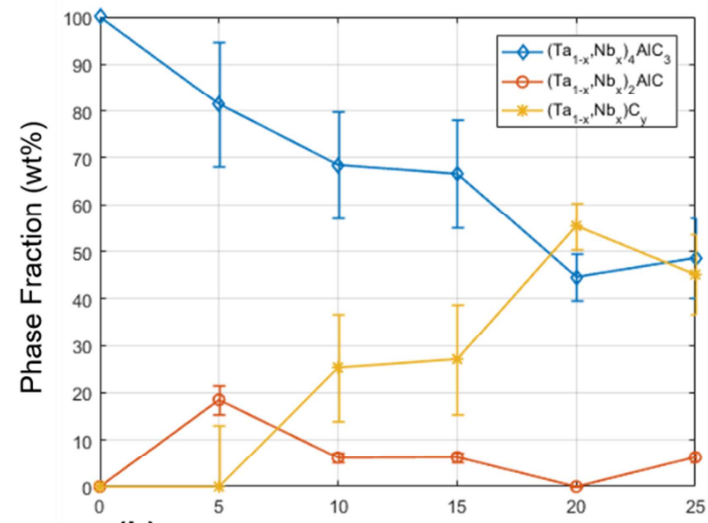

(b) $\quad \mathrm{x}=\mathrm{Nb} /(\mathrm{Nb}+\mathrm{Ta})(\mathrm{mol} \%)$

Fig. 2. (a) Relative abundance of the 413 and 211 MAX phases, and the $\left(T a_{1-x}, M_{x}^{\prime}\right) C_{y}$ pseudo-binary carbides as function of $\mathrm{x}$, in the produced $\left(\mathrm{Ta}_{1-\mathrm{x}}, \mathrm{Hf}_{\mathrm{x}}\right)_{4} \mathrm{AlC}_{3}$ and $(\mathrm{b})\left(\mathrm{Ta}_{1-}\right.$ $\left.{ }_{x}, \mathrm{Nb}_{\mathrm{x}}\right)_{4} \mathrm{AlC}_{3}$ ceramics. 

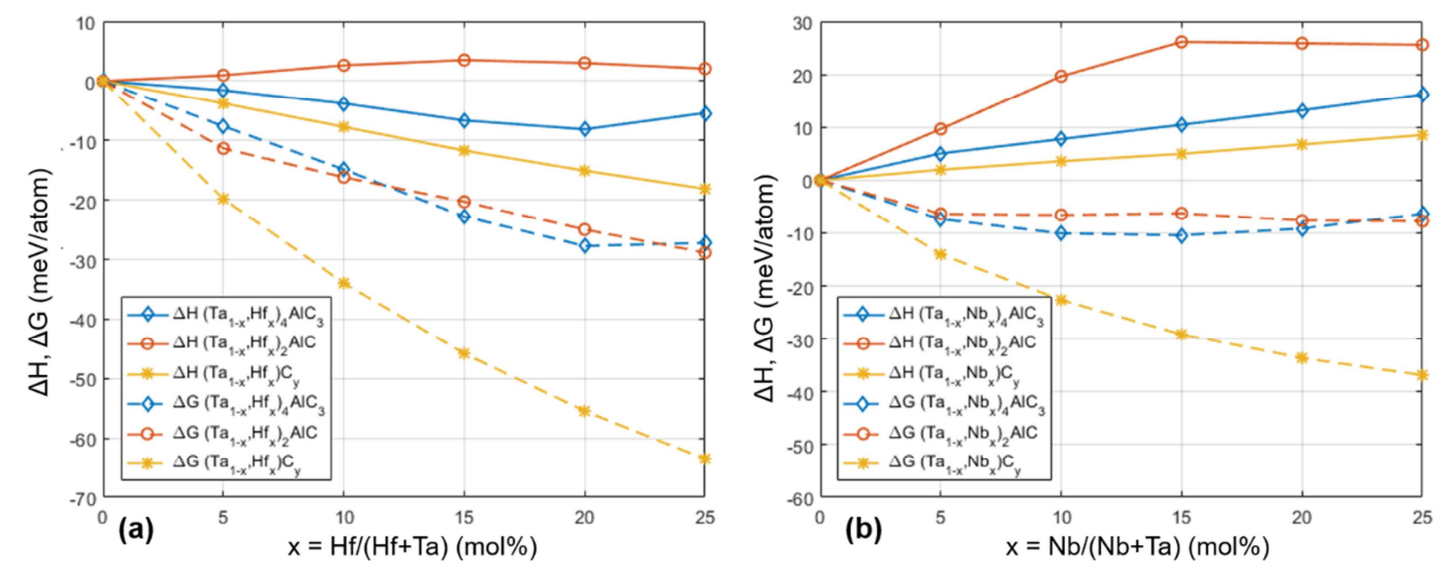

Fig. 3. Calculated formation enthalpy, $\Delta \mathrm{H}$, at $0 \mathrm{~K}$ and Gibbs free energy of formation, $\Delta \mathrm{G}$, at $1873 \mathrm{~K}$ as function of $\mathrm{x}$ for (a) $\left(\mathrm{Ta}_{1-\mathrm{x}}, \mathrm{Hf}_{\mathrm{x}}\right)_{4} \mathrm{AlC}_{3},\left(\mathrm{Ta}_{1-\mathrm{x}}, \mathrm{Hf}_{\mathrm{x}}\right)_{2} \mathrm{AIC}$, and $\left(\mathrm{Ta}_{1-\mathrm{x}}, \mathrm{Hf}_{\mathrm{x}}\right) \mathrm{C}$ phases, and (b) $\left(\mathrm{Ta}_{1-\mathrm{x}}, \mathrm{Nb}_{\mathrm{x}}\right)_{4} \mathrm{AlC}_{3},\left(\mathrm{Ta}_{1-\mathrm{x}}, \mathrm{Nb}_{\mathrm{x}}\right)_{2} \mathrm{AIC}$, and $\left(\mathrm{Ta}_{1-\mathrm{x}}, \mathrm{Nb}_{\mathrm{x}}\right) \mathrm{C}$ phases.
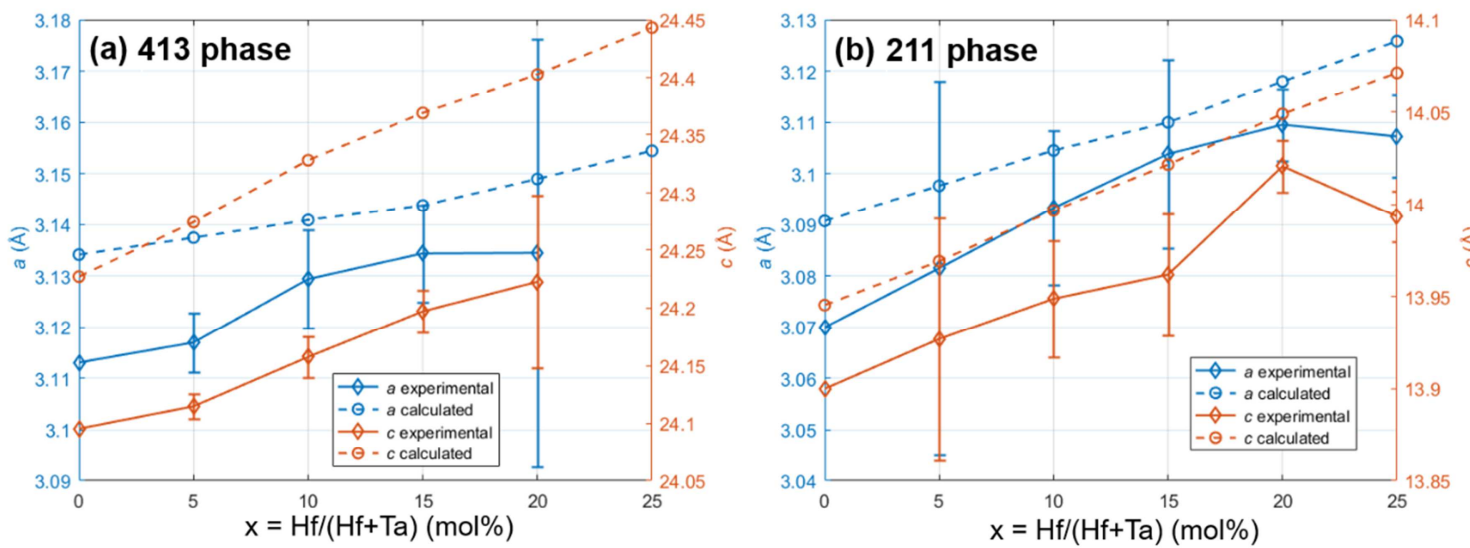

Fig. 4. Measured and calculated lattice parameters $a$ and $c$ for the (a) $\left(\mathrm{Ta}_{1-\mathrm{x}}, \mathrm{Hf}_{\mathrm{x}}\right)_{4} \mathrm{AlC}_{3}$ and (b) $\left(\mathrm{Ta}_{1-\mathrm{x}}, \mathrm{Hf}_{\mathrm{x}}\right)_{2} \mathrm{AIC}$ MAX phase solid solutions.
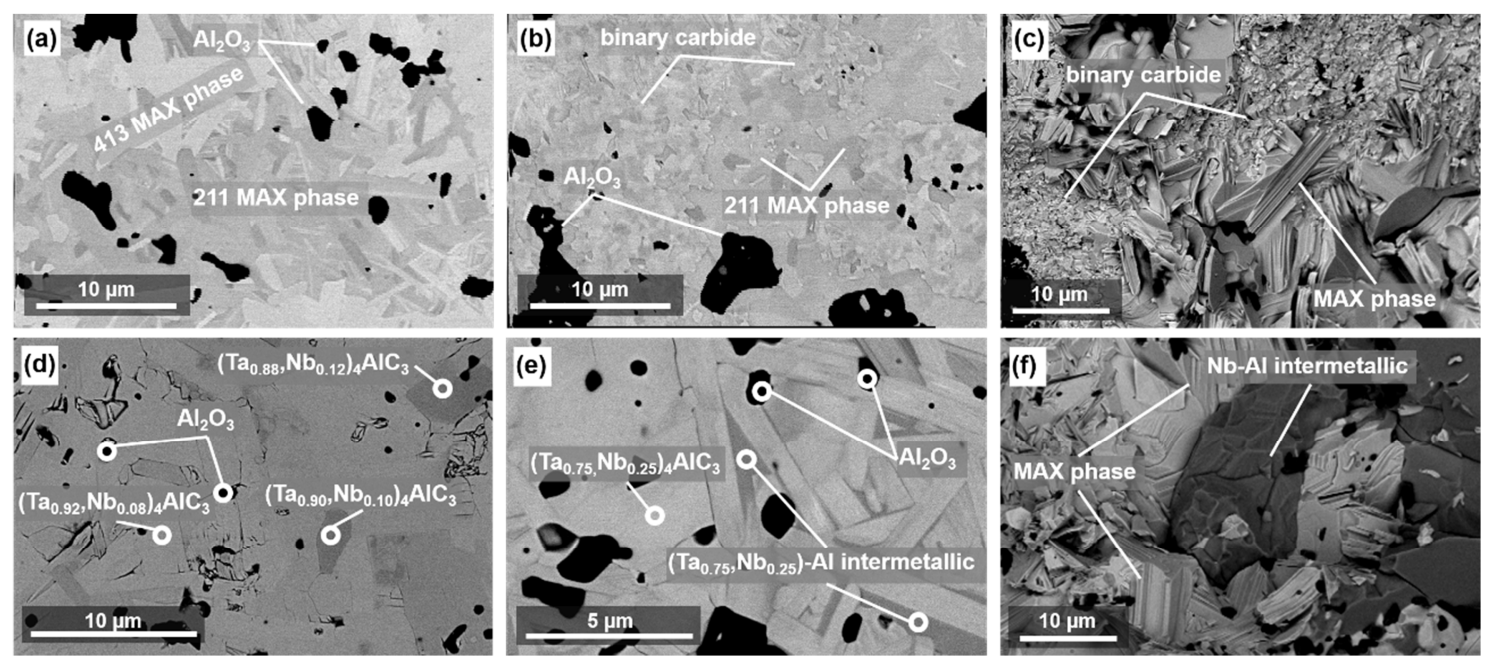

Fig. 5. BSE images of the microstructure of (a) TH10, (b) TH25, (d) TN10 and (e) TN25; the latter two include several EDS point analyses. Fracture surfaces of (c) TH25 and (f) TN25; the latter shows the presence of $\mathrm{Nb}-\mathrm{Al}$ intermetallics. 

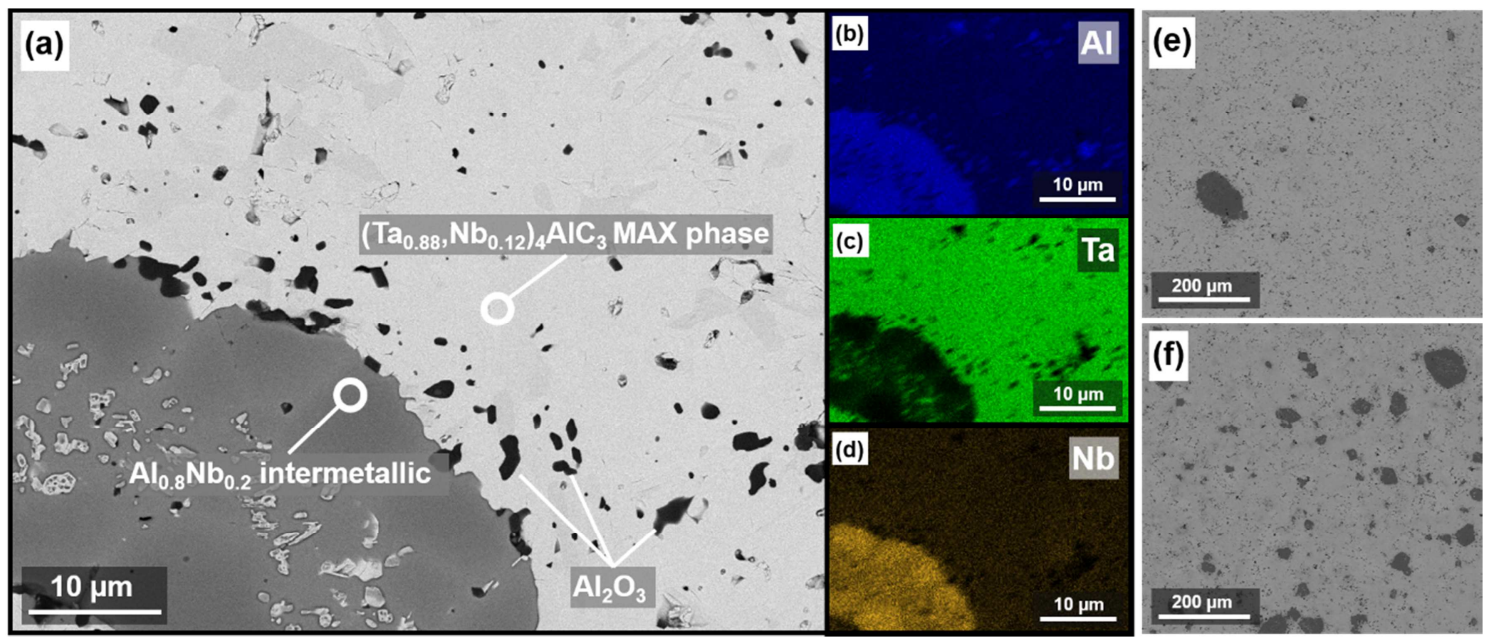

Fig. 6. (a) BSE image of the TN10 grade microstructure, showing a MAX phase region enveloping $\mathrm{Nb}$-rich $\mathrm{Nb}-\mathrm{Al}$ intermetallics. (b-d) EDS maps of $\mathrm{Al}, \mathrm{Ta}$, and $\mathrm{Nb}$. BSE images of the relative abundance of $\mathrm{Nb}-\mathrm{Al}$ intermetallics (dark spots) in TN10 (e) and TN25 (f).

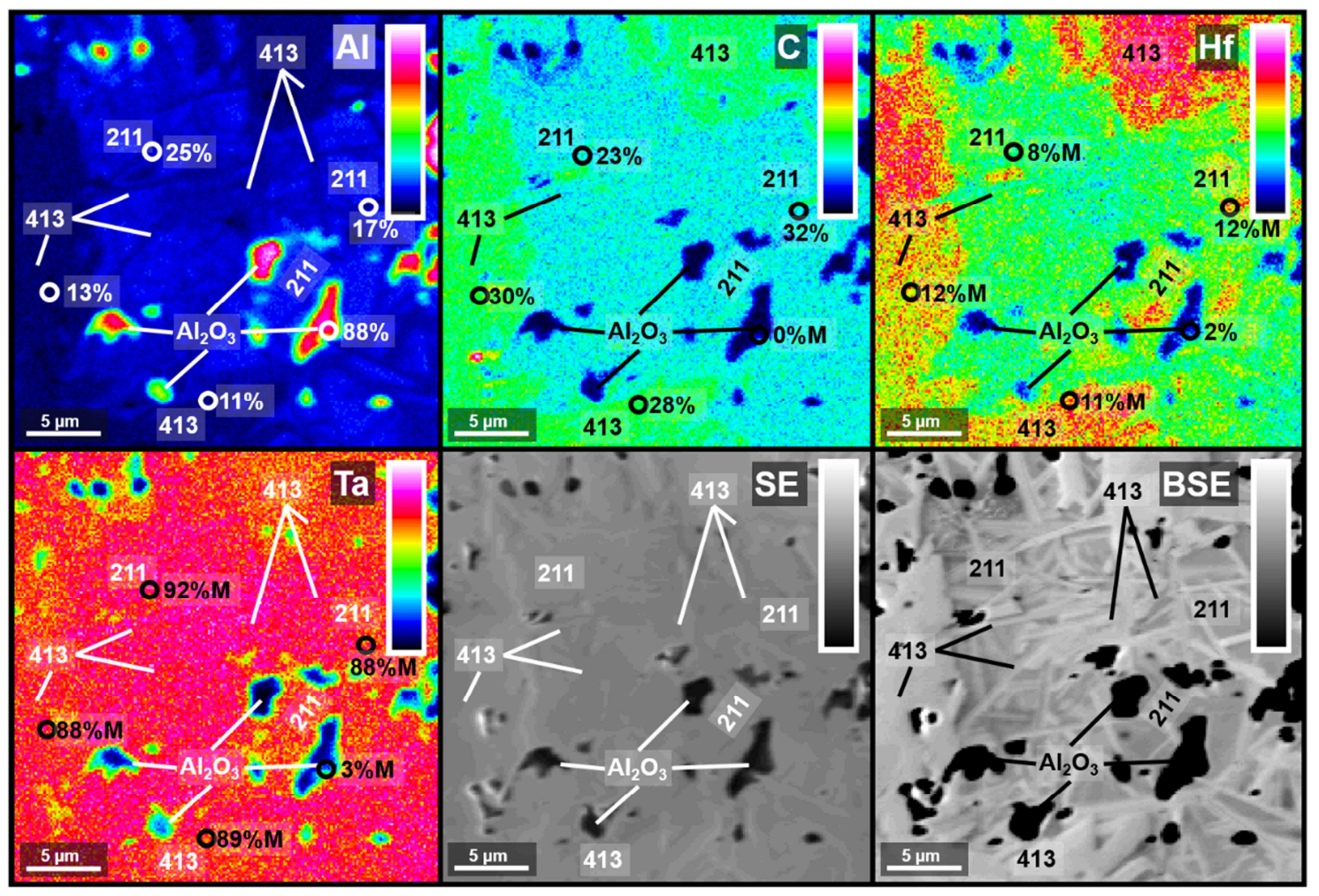

Fig. 7. WDS elemental mapping of grade TH10. The distribution of $\mathrm{Al}, \mathrm{C}, \mathrm{Hf}$ and $\mathrm{Ta}$ is shown along with secondary electron (SE) and BSE images of the area of interest. The composition is quantified at given points (circles), $\mathrm{Ta}$ and $\mathrm{Hf}$ are given as at\% of the $\mathrm{M}$ element. 


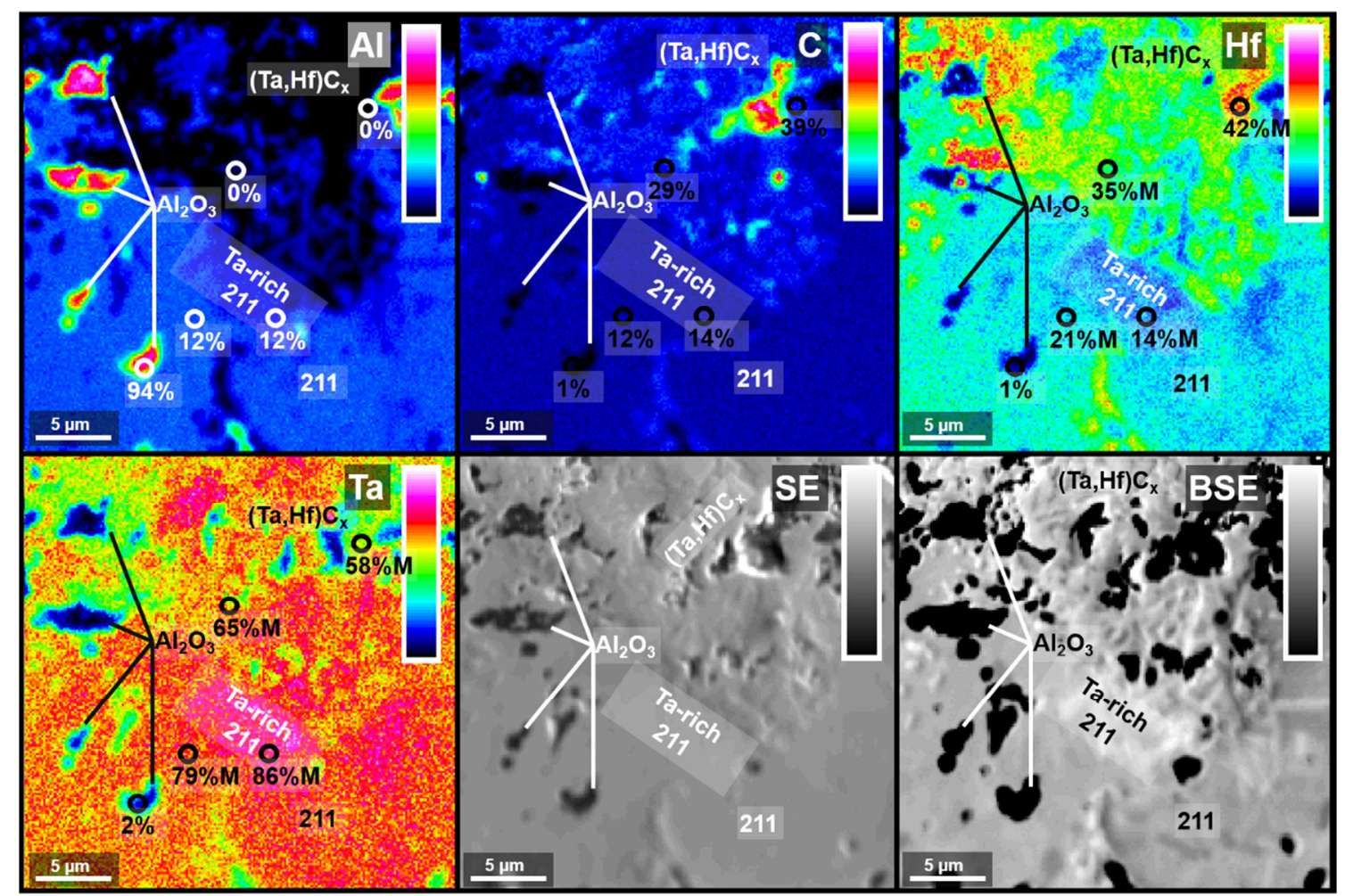

Fig. 8. WDS elemental mapping of grade $\mathrm{TH} 25$. The distribution of $\mathrm{Al}, \mathrm{C}, \mathrm{Hf}$ and $\mathrm{Ta}$ is shown along with SE and BSE images of the area of interest. The composition is quantified at given points (circles), $\mathrm{Ta}$ and $\mathrm{Hf}$ are given as at\% of the $\mathrm{M}$ element.
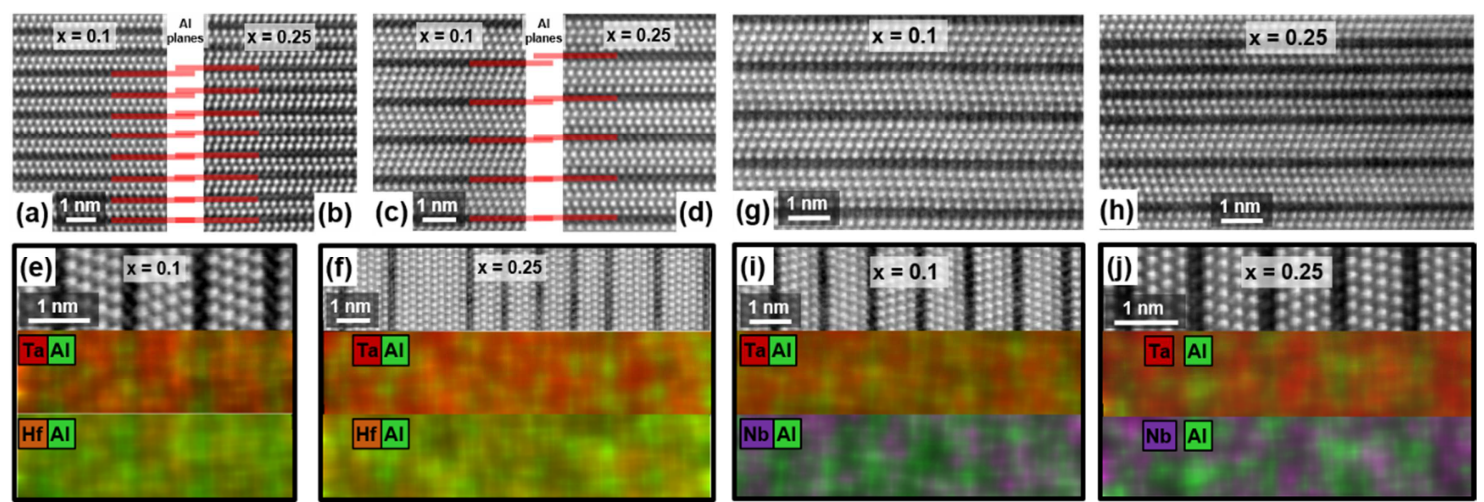

Fig. 9. STEM images of 211 atomic stacks in the (a) TH10 (a) and (b) TH25 grades; (c) 413 atomic stacks in the TH10 grade; and (d) 2nAB+Al stacks in the TH25 grade. The location of the darker $\mathrm{Al}$ planes is shown by red lines. TEM/EDS maps of $\mathrm{Al}$, Ta and $\mathrm{Hf}$ in select areas of interest in the (e) TH10 and (f) TH25 grades. STEM images of (g) a 413 atomic stack in the TN10 grade, and (h) a mixed 413-211 stacking in the TN25 grade. TEM/EDS maps of Al, Ta and Nb in 413 areas in the (i) TN10 and (j) TN25 grades. 


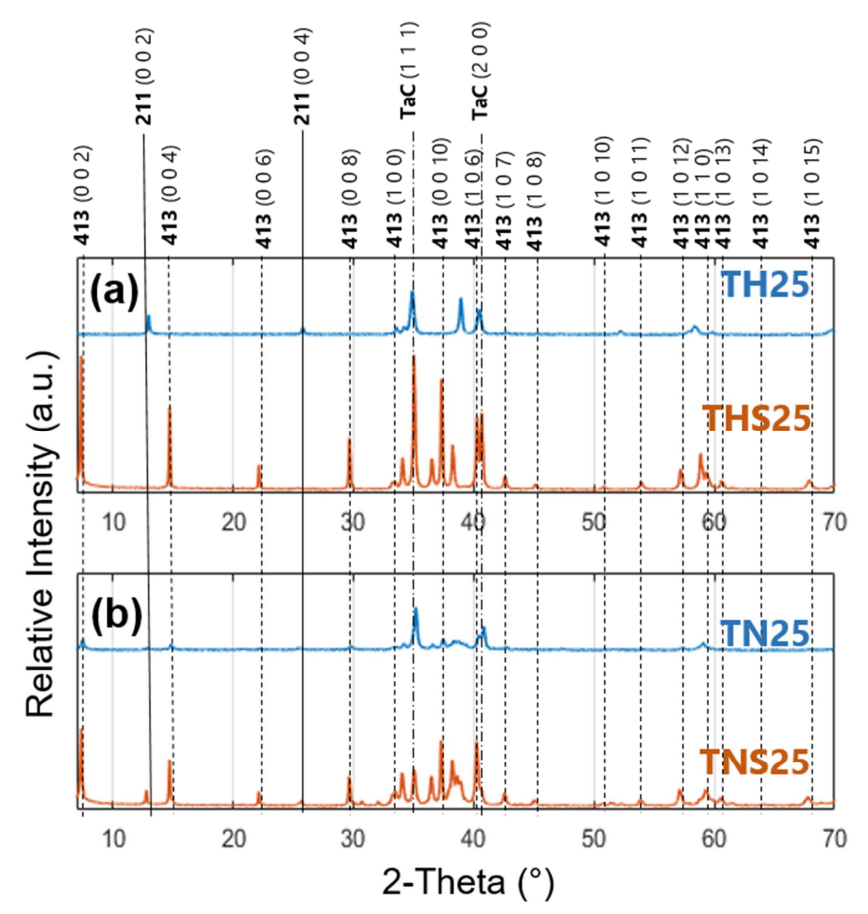

Fig. 10. XRD patterns of (a) the TH25 and THS25 grades, and (b) the TN25 and TNS25 grades.
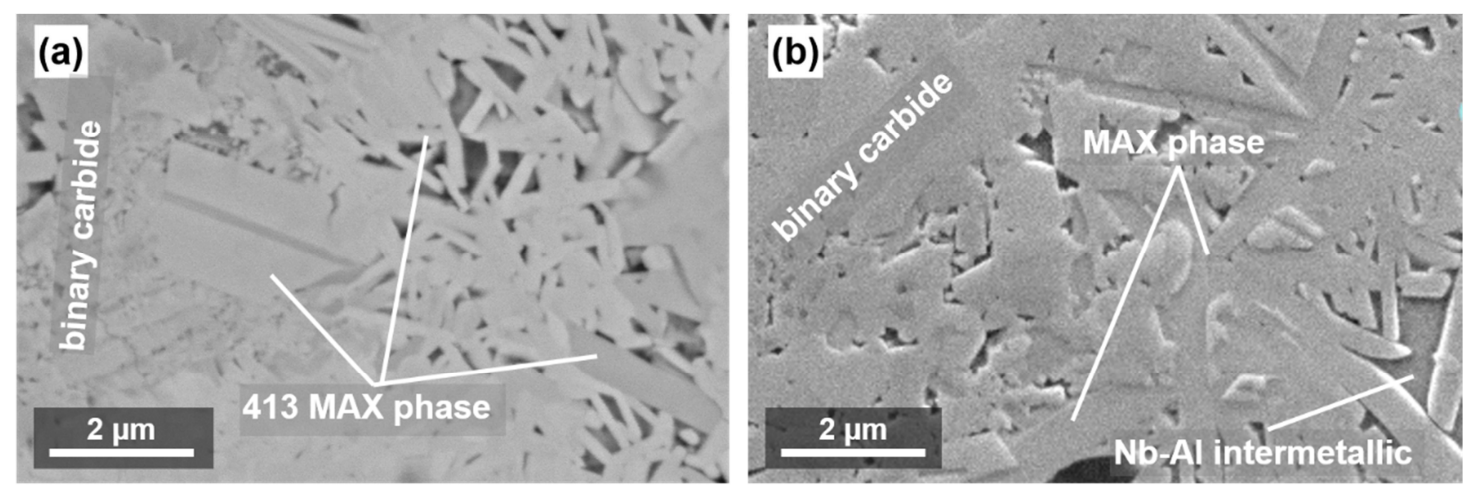

Fig. 11. SEM images of the microstructure of the (a) THS25 and (b) TNS25 grades.

Table 1. Phase assembly of the THS25, TH25, TNS25, and TN25 grades, where M' is $\mathrm{Hf}$ or $\mathrm{Nb}$.

\begin{tabular}{|c|c|c|c|c|}
\hline Grade & THS25 & TH25 & TNS25 & TN25 \\
\hline $413(w t \%)$ & 62.8 & 0.0 & 74.6 & 48.6 \\
\hline $211(w t \%)$ & 0.0 & 62.5 & 19.6 & 6.3 \\
\hline (Ta,M')C (wt\%) & 39.2 & 39.5 & 5.8 & 45.1 \\
\hline
\end{tabular}

